Elsevier required licence: (C) <2017>. This manuscript version is made available under the CC-BY-NC-ND 4.0 license http://creativecommons.org/licenses/by-nc-nd/4.0/ 

1

\title{
Osmotic versus conventional membrane bioreactors integrated with reverse osmosis for water reuse: Biological stability, membrane fouling, and contaminant removal
}

\author{
Fresh manuscript submitted to Water Research \\ November 2016
Wenhai Luo ${ }^{\text {a }}$, Hop V. Phan ${ }^{\text {a }}$, Ming Xie ${ }^{\text {b }}$, Faisal I. Hai ${ }^{\text {a }}$, William E. Price ${ }^{\mathrm{c}}$, Menachem Elimelech ${ }^{\mathrm{d}}$, Long D. Nghiem ${ }^{\mathrm{a}^{*}}$
${ }^{\text {a }}$ Strategic Water Infrastructure Laboratory, School of Civil, Mining and Environmental Engineering, University of Wollongong, Wollongong, NSW 2522, Australia University, Melbourne, VIC 8001, Australia \\ ${ }^{\mathrm{b}}$ Institute for Sustainability and Innovation, College of Engineering and Science, Victoria \\ ${ }^{\mathrm{c}}$ Strategic Water Infrastructure Laboratory, School of Chemistry, University of Wollongong, \\ ${ }^{\mathrm{d}}$ Department of Chemical and Environmental Engineering, Yale University, New Haven, \\ Connecticut 06520-8286, United States
}

\footnotetext{
* Corresponding author: longn@uow.edu.au; Ph: +61 (2) 42214590.
} 


\section{Abstract}

15 This study systematically compares the performance of osmotic membrane bioreactor 16 reverse osmosis (OMBR-RO) and conventional membrane bioreactor - reverse osmosis 17 (MBR-RO) for advanced wastewater treatment and water reuse. Both systems achieved 18 effective removal of bulk organic matter and nutrients, and almost complete removal of all 31

19 trace organic contaminants investigated. They both could produce high quality water suitable 20 for recycling applications. During OMBR-RO operation, salinity build-up in the bioreactor 21 reduced the water flux and negatively impacted the system biological treatment by altering 22 biomass characteristics and microbial community structure. In addition, the elevated salinity 23 also increased soluble microbial products and extracellular polymeric substances in the mixed 24 liquor, which induced fouling of the forward osmosis (FO) membrane. Nevertheless, 25 microbial analysis indicated that salinity stress resulted in the development of halotolerant 26 bacteria, maintaining the OMBR system biologically active. By contrast, biological 27 performance was relatively stable throughout conventional MBR-RO operation. Compared to conventional MBR-RO, the FO process effectively prevented foulants from permeating into the draw solution, thereby significantly reducing fouling of the downstream RO membrane in

30 OMBR-RO operation. Accumulation of organic matter, including humic- and protein-like 31 substances, as well as inorganic salts in the MBR effluent resulted in severe RO membrane 32 fouling in conventional MBR-RO operation.

33 Keywords: Osmotic membrane bioreactor (OMBR); forward osmosis (FO); reverse osmosis 34 (RO); trace organic contaminants (TrOCs); membrane fouling. 


\section{Introduction}

36 Water scarcity due to population growth, urbanization, climate change, and environmental

37 pollution is a vexing challenge to the sustainable development of our society (Elimelech and

38 Phillip, 2011). This challenge calls for further efforts to develop and improve technologies that can tap into alternative water sources, such as municipal wastewater, to enhance water supply and mitigate water shortage. The ubiquitous presence of trace organic contaminants (TrOCs) in reclaimed water and wastewater-impacted water bodies remains a major obstacle to water reuse. TrOCs are emerging organic chemicals of significant concerns derived from either anthropogenic or natural activities as they present potential health risks to humans and other living organisms (Luo et al., 2014b).

Membrane bioreactor (MBR) is a well-known technology for wastewater treatment and water reuse. MBR combines conventional activated sludge (CAS) treatment and a physical membrane filtration process, typically including microfiltration (MF) and ultrafiltration (UF). As an alternative to CAS treatment, $\mathrm{MBR}$ is more robust and versatile and can produce higher standard effluent with smaller sludge production and physical footprint (Hai et al., 2014). Some evidence has emerged that MBR could enhance the removal of TrOCs, 51 particularly moderately biodegradable and hydrophobic compounds compared to CAS treatment (Clara et al., 2005; De Wever et al., 2007). However, some hydrophilic TrOCs are still poorly removed by MBR due to their resistance to biodegradation and low adsorption onto sludge (Tadkaew et al., 2011; Nguyen et al., 2013; Wijekoon et al., 2013). Thus, further treatment by nanofiltration (NF) or reverse osmosis (RO) is usually required to produce high quality water for reuse (Gerrity et al., 2013). The NF/RO process can complement well MBR to achieve effective removal of various TrOCs (Alturki et al., 2010; Nguyen et al., 2013). 
Recent progress in water reuse has led to the emergence of a new variation of MBR, namely, osmotic membrane bioreactor (OMBR) (Achilli et al., 2009; Cornelissen et al., 2011; Chen et al., 2014; Nguyen et al., 2016). During OMBR operation, treated water is extracted from the mixed liquor into a highly concentrated draw solution by the forward osmosis (FO) process. By employing a selective, semi-permeable FO membrane, TrOCs can be retained in the bioreactor and thus increase their biodegradation during OMBR operation (Alturki et al., 2012; Holloway et al., 2014). Moreover, FO has a lower fouling propensity, and when fouling occurs, it is readily reversible compared to pressure-driven membrane processes (Mi and Elimelech, 2010; Kim et al., 2014; Luo et al., 2015a; Xie et al., 2015).

OMBR can be used as a stand-alone process or coupled with a desalination process, such as RO to form an OMBR-RO hybrid system, for draw solution recovery and recycling water production (Luo et al., 2014a). In the latter configuration, the desalination process may provide an additional barrier to further purify the product water. For instance, Holloway et al. (2014) demonstrated that 15 of 20 TrOCs detected in municipal wastewater were removed to below detection limit by OMBR, and compounds that passed through the FO membrane were effectively retained by the subsequent RO process. An effective contaminant removal by OMBR-RO and its potential for advanced wastewater treatment and water reuse were also subsequently highlighted by Luo et al. (2016b). It is noteworthy that an MF or UF membrane was coupled with OMBR in these two studies to control salinity build-up, which is an inherent issue associated with OMBR due to the high salt rejection by the FO membrane and, more importantly, the reverse draw solute flux.

OMBR-RO can offer a range of potential benefits over conventional MBR-RO systems for advanced wastewater treatment and water reuse. Cornelissen et al. (2011) reported that OMBR-RO could reduce the capital cost of wastewater reuse by $5-25 \%$ compared to 
83 depends on the assumption that the cost and water permeability of the FO membrane are 84 comparable to those of the UF membrane. Given the low fouling property of FO compared to $\mathrm{UF}$, there can be also a reduction in operational cost related to membrane cleaning and replacement. Cornelissen et al. (2011) also assumed that the two hybrid systems had the same

87 treatment performance, which was probably conservative as the FO membrane can produce higher quality permeate than the UF membrane. The high quality FO permeate would alleviate membrane fouling in the downstream RO process, which is a major issue for costeffective application of conventional OMBR-RO for water reuse (Farias et al., 2014; Al Ashhab et al., 2014). Thus, additional cost saving for OMBR-RO can potentially be derived

92 from a more stable water production from the downstream RO unit with less frequent 93 cleaning and longer service time in comparison with conventional MBR-RO. Of a particular 94 note, to date, no study has directly compared the performance of OMBR-RO and conventional MBR-RO for water reuse.

This study aims to compare the performance of OMBR-RO with conventional MBR-RO in terms of biological stability, contaminant removal, and membrane fouling. Similar operating parameters were applied to both bioreactors for a systematic comparison. Water production and salinity build-up during OMBR-RO operation were evaluated. High-throughput sequencing technique was applied to elucidate the effect of salinity build-up on microbial community structure during OMBR-RO operation compared to that in conventional MBRRO. Fate and transport behaviours of bulk organic matter, nutrients, and TrOCs in these two 103 hybrid systems were systematically examined. In addition, the fouling behaviour of the RO membrane in both systems was also delineated and compared. 


\section{Materials and methods}

\subsection{Synthetic wastewater and trace organic contaminants}

107 A synthetic wastewater was used in this study. The synthetic wastewater was prepared daily 108 to obtain $100 \mathrm{mg} / \mathrm{L}$ glucose, $100 \mathrm{mg} / \mathrm{L}$ peptone, $17.5 \mathrm{mg} / \mathrm{L} \mathrm{KH}_{2} \mathrm{PO}_{4}, 17.5 \mathrm{mg} / \mathrm{L} \mathrm{MgSO}_{4}, 10$

$109 \mathrm{mg} / \mathrm{L} \mathrm{FeSO}_{4}, 225 \mathrm{mg} / \mathrm{L} \mathrm{CH}_{3} \mathrm{COONa}$, and $35 \mathrm{mg} / \mathrm{L}$ urea (Alturki et al., 2010).

110 A set of 31 TrOCs were selected to represent four major groups of emerging organic

111 chemicals of significant concern - endocrine disrupting compounds, pharmaceutical and

112 personal care products, industrial chemicals, and pesticides — that occur ubiquitously in

113 municipal wastewater. Key physicochemical properties of these TrOCs are summarized in

114 Table S1, Supplementary Data. Based on their effective octanol - water partition coefficient

115 (i.e. $\log \mathrm{D}$ ) at solution $\mathrm{pH}$ 8, the 31 TrOCs could be categorized as hydrophobic (i.e. $\log \mathrm{D}$

116 > 3.2) and hydrophilic (i.e. Log D < 3.2) (Tadkaew et al., 2011). A stock solution containing

$11725 \mu \mathrm{g} / \mathrm{mL}$ of each of TrOCs was prepared in pure methanol and stored at $-18{ }^{\circ} \mathrm{C}$ in the dark.

118 The stock solution was introduced into the synthetic wastewater described above to obtain a

119 concentration of $5 \mu \mathrm{g} / \mathrm{L}$ of each compound. The TrOC stock solution was used within a 120 month.

\subsection{Experimental systems}

\subsubsection{Osmotic membrane bioreactor - reverse osmosis}

123 A lab-scale OMBR-RO system was used (Figure S1a, Supplementary Data). This hybrid 124 system was consisted of a feed solution reservoir, a glass bioreactor with a submerged, plate125 and-frame FO membrane cell, a draw solution reservoir, and a cross-flow RO unit. A water 126 level controller was used to regulate a Masterflex peristaltic pump (Cole-Parmer, Vernon

127 Hills, IL) to feed the bioreactor. The feed reservoir was positioned on a digital balance 
128 (Mettler-Toledo, Hightstown, IL), which was connected to a computer. A decrease in the feed reservoir weight was recorded and then used to calculate the FO water flux.

130 The FO membrane cell was made of acrylic plastic. A flat-sheet, thin-film composite (TFC)

131 FO membrane was mounted on the cell to seal the draw solution flow channel of $20 \mathrm{~cm}$ long,

$13215 \mathrm{~cm}$ wide, and $0.4 \mathrm{~cm}$ high. The membrane active layer was in contact with the mixed

133 liquor (i.e. FO mode) with an effective surface area of $300 \mathrm{~cm}^{2}$. The draw solution was 134 circulated from a stainless steel reservoir to the membrane cell by a gear pump (Micropump,

135 Vancouver, WA) at a cross-flow velocity of $2.8 \mathrm{~cm} / \mathrm{s}$.

136 The TFC FO membrane used in this study was obtained from Hydration Technology

137 Innovations (Albany, OR). Similar to TFC FO membranes from other suppliers (e.g. Oasys

138 Water and Porifera), this membrane comprised a thin, selective polyamide active layer and a

139 porous polysulfone support layer. These TFC FO membranes have higher rejection capacity

140 and much higher water permeability than cellulose triacetate based FO membranes (Cath et

141 al., 2013). In fact, TFC FO membranes with two to three times higher water permeability

142 than the membrane used in this study have been recently reported (Tian et al., 2015; Wei et

143 al., 2015). It is noted that the polyamide active layer of commercial membranes can be

144 slightly modified by proprietary additives. In addition, the support layer structure can also 145 influence the membrane water permeability ( $\mathrm{Lu}$ et al., 2015). However, this study was 146 specific to the comparison between OMBR and conventional MBR, rather than membrane 147 properties. Thus, findings from this study are still valid to OMBR using other FO 148 membranes.

149 The cross-flow RO unit, comprising a Hydra-Cell high pressure pump (Wanner Engineering,

150 Minneapolis, MN) and a membrane cell made of stainless steel, was coupled with OMBR to 151 reconcentrate the draw solution and produce recycling water. A flat-sheet, TFC polyamide 152 RO membrane (LFC3, Hydranautics, Oceanside, CA) was embedded into the membrane cell 
153 with a flow channel height of $0.2 \mathrm{~cm}$ and an effective membrane surface area of $40 \mathrm{~cm}^{2}(4 \mathrm{~cm}$

$154 \times 10 \mathrm{~cm}$ ). A bypass valve and a back-pressure regulator (Swagelok, Solon, $\mathrm{OH}$ ) were used to

155 adjust the hydraulic pressure and cross-flow velocity. A temperature controller (Neslab

156 RTE7, Waltham, MA) installed with a stainless steel heat exchanger coil was used to

157 maintain the RO feed (i.e. OMBR draw solution) temperature at $21 \pm 1{ }^{\circ} \mathrm{C}$. Water flux was

158 monitored by a digital flow meter (Optiflow, Palo Alto, CA), which was connected to a 159 computer. Key properties of the FO and RO membranes used in the OMBR-RO hybrid 160 system are provided in Table S2, Supplementary Data.

\subsubsection{Conventional membrane bioreactor - reverse osmosis}

162 A lab-scale, conventional MBR-RO system was composed of a hollow fibre MF membrane

163 module (Mitsubishi Rayon Engineering, Tokyo, Japan) in a glass bioreactor and an RO unit 164 (Figure S1b, Supplementary Data). The bioreactor and RO unit were identical to those used in the OMBR-RO system. The MF membrane was made of polyvinylidene fluoride with a nominal pore size and an effective surface area of $0.4 \mu \mathrm{m}$ and $740 \mathrm{~cm}^{2}$, respectively. The MF membrane driven by a Masterflex peristaltic pump (Cole-Parmer, Vernon Hills, IL) was operated in a cycle of 14 min suction and 1 min relaxation. The relaxation time was set to

169 reduce membrane fouling. A high resolution $( \pm 0.1 \mathrm{kPa})$ pressure sensor (Extech Equipment, 170 Australia) was installed to record the trans-membrane pressure (TMP).

\subsection{Experimental protocol}

172 Activated sludge from the Wollongong Wastewater Treatment Plant (Wollongong, Australia)

173 was used to inoculate the two bioreactors. The bioreactors were acclimatized to the synthetic

174 wastewater described above for over 60 days using MF membranes for effluent extraction

175 under the same conditions. Once acclimatized with regards to bulk organic removal (i.e. over $17697 \%$ total organic carbon (TOC) removal), the MF membrane was removed from one 
177 bioreactor, which was then integrated with the FO and RO components to form the OMBR-

178 RO hybrid system. A same RO component was coupled with the other bioreactor to establish

179 the conventional MBR-RO system.

180 Both OMBR-RO and conventional MBR-RO systems were continuously operated for 40

181 days under similar conditions in a constant temperature room $\left(22 \pm 1^{\circ} \mathrm{C}\right)$. The bioreactors

182 with working volume of $6 \mathrm{~L}$ were continuously aerated to obtain a mixed liquor dissolved 183 oxygen (DO) concentration of $5 \pm 1 \mathrm{mg} / \mathrm{L}$. The initial mixed liquor suspended solids (MLSS)

184 concentration was adjusted to approximately $5 \mathrm{~g} / \mathrm{L}$. The sludge retention time (SRT) was

185 controlled at 20 days by daily wasting $300 \mathrm{~mL}$ mixed liquor. The hydraulic retention time

186 (HRT) was in the range of $27-60$ hours determined by the water flux of OMBR. A $0.5 \mathrm{M}$

$187 \mathrm{NaCl}$ draw solution (with effective volume of $10 \mathrm{~L}$ ) was used for OMBR. On day $20,100 \mathrm{~g}$

$188 \mathrm{NaCl}$ was added to replenish draw solute loss caused by the reverse salt flux and its passage

189 through the downstream RO membrane. This amount was calculated based on a decrease in

190 the electrical conductivity of the draw solution and a $\mathrm{NaCl}$ calibration curve.

191 Water flux of the conventional MBR was adjusted daily to be equal to that of OMBR to

192 systematically compare their effects on the downstream RO process. At the same time, the

193 RO water flux was also adjusted accordingly by regulating the applied hydraulic pressure

194 while fixing the cross-flow velocity at $41.7 \mathrm{~cm} / \mathrm{s}$. As a result, the working volume of the draw

195 solution and MBR effluent was constant at $10 \mathrm{~L}$ over the entire experimental period. No

196 membrane cleaning was conducted for both systems during their operation. A new RO

197 membrane was used once its normalized water permeability decreased to 0.2. 


\subsubsection{Measurement of basic water quality parameters}

200 Basic water quality parameters were analysed every three days. Specifically, TOC and total

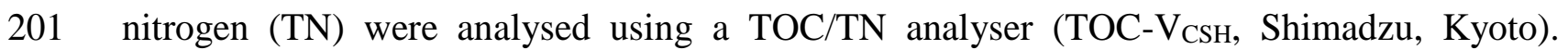

202 Ammonium $\left(\mathrm{NH}_{4}{ }^{+}\right)$and orthophosphate $\left(\mathrm{PO}_{4}^{3-}\right)$ were determined by a Flow Injection

203 Analysis system (QuikChem 8500, Lachat, CO). An Orion 4-Star Plus pH/conductivity meter

204 (Thermo Scientific, Waltham, MA) was used to monitor the solution $\mathrm{pH}$ and electrical 205 conductivity on a daily basis.

\subsubsection{Measurement of trace organic contaminants}

207 Aqueous samples were taken from the OMBR-RO and MBR-RO systems every ten days for 208 TrOC analysis using a method previously described by Hai et al. (2011). Briefly, the method 209 involved solid phase extraction, derivatisation, and quantification by a gas chromatography 210 mass spectrometry system (QP5000 GC-MS, Shimadzu, Kyoto).

211 In OMBR-RO, TrOC removal rates by the bioreactor $\left(R_{B i o}\right)$, OMBR $\left(R_{O M B R}\right)$, and OMBR-RO

212 (Roverall) are defined as follows:

$213 \quad R_{B i o}=\left(1-\frac{C_{S u p} V_{B i o}+C^{*}{ }_{\text {Draw }} \Delta V_{F O}}{C_{F e e d} \Delta V}\right) \times 100 \%$

$214 \quad R_{\text {OMBR }}=\left(1-\frac{C^{*} \text { Draw }}{C_{\text {Feed }}}\right) \times 100 \%$

$215 R_{\text {Overall }}=\left(1-\frac{C_{\text {Permeate }}}{C_{\text {Feed }}}\right) \times 100 \%$

216 where $C_{F e e d}, C_{\text {Sup }}$, and $C_{\text {Permeate }}$ is the measured $\operatorname{TrOC}$ concentration $(\mathrm{ng} / \mathrm{L})$ in the feed, mixed

217 liquor supernatant, and RO permeate, respectively; $C_{\text {Draw }}^{*}$ is the TrOC concentration in the

218 FO permeate; $V_{B i o}$ is the effective bioreactor volume (i.e. $6 \mathrm{~L}$ ); and $\Delta V_{F O}$ is the volume of 
219 water passed through the FO membrane between time $t$ and $t+\Delta t$. TrOCs accumulate in the 220 draw solution when they pass through the FO membrane but are retained by the subsequent 221 RO membrane (D'Haese et al., 2013). Thus, $C^{*}$ Draw is determined from a mass balance:

$222 \quad C^{*}{ }_{\text {Draw }}=\frac{M_{F O}}{Q_{F O}}$

$223 \quad M_{F O}=\frac{V_{\text {Draw }}\left(C_{\text {Draw } t+\Delta t)}-C_{\text {Draw }(t)}\right)}{\Delta t}+\frac{\frac{\left(C_{R O(H \Delta t)}+C_{R O(t)}\right)}{2} \Delta V}{\Delta t}$

$224 \Delta V=Q_{R O} \Delta t$

225 where $M_{F O}$ is the mass flow rate of TrOCs crossed through the FO membrane; $C_{\operatorname{Draw}(t)}$ and $226 C_{\operatorname{Draw}(t+\Delta t)}$ is the measured TrOC concentration in the draw solution at time $t$ and $t+\Delta t$, 227 respectively; $C_{R O(t)}$ and $C_{R O(t+\Delta t)}$ is the measured $\mathrm{TrOC}$ concentration in the RO permeate at 228 time $t$ and $t+\Delta t$, respectively; and $Q_{F O}$ and $Q_{R O}$ is the water flux of the FO and RO 229 membranes, respectively. As noted in Section 2.3, the RO water flux $\left(Q_{R O}\right)$ was adjusted to 230 be equal to that of the FO membrane $\left(Q_{F O}\right)$. Based on eqs. $(4)-(6), C^{*}$ Draw is calculated from

$C_{\text {Draw }}^{*}=\frac{V_{\text {Draw }}\left(C_{D r a w(A \Delta t)}-C_{D r a w(t)}\right)}{\Delta V_{F O}}+\frac{\left(C_{R O(\sharp \Delta t)}+C_{R O(t)}\right)}{2}$

232 According to eqs. (1) - (3), the observed TrOC rejection rate by the FO $\left(R_{O b F O}\right)$ and $\mathrm{RO}\left(R_{O b}\right.$ $233 R O$ ) membranes is calculated as:

$234 R_{O b F O}=R_{O M B R}-R_{B i o}$

$R_{\text {ObRO }}=R_{\text {Overall }}-R_{\text {OMBR }}$

236 The observed TrOC rejection rate does not reflect the real separation capacity of the FO and 237 RO membranes, but can be used to infer their contributions to TrOC removal in OMBR-RO. 238 Similar to OMBR-RO operation, the RO water flux was adjusted daily to match the MBR 
239 effluent flow rate, maintaining the effluent reservoir with a working volume of $10 \mathrm{~L}$ during

240 conventional MBR-RO operation (Section 2.3). Therefore, the calculation process listed

241 above was also applicable to evaluate TrOC removal by different compartments of

242 conventional MBR-RO.

\section{$243 \quad 2.4 .3 \quad$ Fluorescence excitation-emission matrix spectroscopy}

244 Fluorescence intensities of the OMBR and MBR mixed liquor supernatant, draw solution, 245 and MBR effluent samples at the beginning and conclusion of OMBR-RO and conventional 246 MBR-RO operation were measured to determine organic substances likely responsible for

247 fouling of the RO membrane using a two-dimensional fluorescence spectrophotometer 248 (Perkin-Elmer LS-55) with excitation wavelengths between 240 and $450 \mathrm{~nm}$ and emission 249 wavelengths between 290 and $580 \mathrm{~nm}$ (in $5 \mathrm{~nm}$ increments). Samples were prepared and 250 analysed based on the method reported by Cory and McKnight (2005). Fluorophores detected 251 in certain areas of optical space in an excitation-emission-intensity matrix (EEM) correspond 252 to specific fractions of dissolved organic matter (Henderson et al., 2009; Xie and Gray, 2016). 253 All samples were diluted to a same TOC concentration for resolving and comparing EEM 254 spectra.

\subsubsection{Microbial community analysis}

256 Sludge samples were taken at the beginning and conclusion of OMBR and conventional 257 MBR operation for microbial community analysis according to a method reported previously 258 by Luo et al. (2016c). In brief, the method included DNA extraction using the FastDNA ${ }^{\circledR}$ 259 SPIN Kit for soil (MP Biomedicals, Santa Ana, CA), PCR amplification of V1 - V3 16S 260 rRNA gene, and amplicon sequencing on a Illumina MiSeq platform (Australian Genome 261 Research Facility, Queensland, Australia). 
262 Paired-end reads were assembled using PEAR (version 0.9.8) (Zhang et al., 2014) and then 263 processed with Quantitative Insights into Microbial Ecology (QIIME 1.9.1) (Caporaso et al., 264 2010), USEARCH (version 8.0.1623) (Edgar, 2013), and UPARSE pipeline. All sequencing 265 data here are available at the Sequence Read Archive (accession number: SRP072961) in the

266 National Centre for Biotechnology Information (Bethesda, MD).

\subsubsection{Biomass characterisation}

268 MLSS and mixed liquor volatile suspended solids (MLVSS) concentrations in the bioreactor were analysed based on Standard Method 2540 (APHA, 2005). Biomass activity was evaluated by determining the specific oxygen uptake rate (SOUR) of activated sludge using Standard Method 1683 (APHA, 2005). Extracellular polymeric substance (EPS) in the sludge were extracted using a method from Zhang et al. (1999). EPS and soluble microbial products

273 (SMP) in the mixed liquor were measured by analysing their protein and polysaccharide concentrations. Proteins and polysaccharides were determined by the Folin method with bovine serum albumin as the standard and the phenol-sulfuric acid method with glucose as the standard, respectively (Semblante et al., 2015).

\subsubsection{Membrane autopsy}

278 At the conclusion of OMBR-RO and conventional MBR-RO operation, a scanning electron

279 microscopy (SEM) coupled with energy dispersive spectroscopy (EDS) (JCM-6000, JEOL, 280 Tokyo, Japan) was used to identify the morphology and composition of the fouling layer on 281 the membrane surface. Membrane samples were air-dried in a desiccator before being coated 282 with an ultra-thin gold layer with a sputter coater (SPI Module, West Chester, PA) for SEM 283 imaging. Attenuated Total Reflection - Fourier Transform Infrared (ATR-FTIR) 284 spectroscopy (IRAffinity-1, Shimadzu, Kyoto, Japan) was also used to probe the chemical composition of the fouling layer. The measured spectrum ranged between 600 and $4000 \mathrm{~cm}^{-1}$ 
286 with $2 \mathrm{~cm}^{-1}$ resolution. Each scan was performed 20 times. A background correction was

287 conducted before each measurement.

\section{3. Results and discussion}

\subsection{Process performance}

\subsubsection{Mixed liquor salinity and water flux}

291 Salinity build-up in the bioreactor is an inherent issue associated with OMBR due to the

292 effective salt rejection by the FO membrane and the reverse draw solute flux. Thus, the

293 mixed liquor conductivity increased significantly within the first 10 days of OMBR operation

294 (Figure 1). Less significant conductivity increase was observed thereafter, which could be 295 attributed to a decrease in the reverse draw solute flux associated with the water flux decline.

296 At the same time, daily sludge wastage to control the SRT could also remove some dissolved

297 inorganic salts, contributing to a more gradual conductivity increase from day 10 onward

298 (Figure 1). High salinity could negatively affect the system biological stability and membrane

299 performance (Lay et al., 2010). Since salinity build-up continued to occur, a long term study

300 is necessary to determine the steady state level of salinity in the bioreactor. It is also noted

301 that several strategies to mitigate salinity build-up in OMBR have been proposed, for

302 example, by using organic draw solutions (Luo et al., 2016a) and integrating with the MF/UF

303 membrane for salt bleeding (Holloway et al., 2015; Luo et al., 2016b).

304 In contrast to salinity build-up in OMBR, the mixed liquor conductivity was constant at 305 approximately $0.38 \mathrm{mS} / \mathrm{cm}$ (corresponding to $0.19 \mathrm{~g} / \mathrm{L} \mathrm{NaCl}$ ) throughout conventional MBR 306 operation (Figure 1). This is because the MF membrane does not retain any dissolved salts.

307 Overall, different sludge characteristics, microbial community structure, and biological 308 treatment performance between OMBR and conventional MBR were observed as discussed 309 in the following sections. 
311 A continuous decrease in the water flux was observed for OMBR (Figure 1). The observed

312 flux decline could be ascribed to salinity build-up in the bioreactor, a decrease in the draw

313 solution concentration, and membrane fouling. Although the RO membrane effectively

314 rejected $\mathrm{NaCl}$ solute (>98\%), the draw solution concentration decreased over time (Figure S2,

315 Supplementary Data), due to the reverse solute transport and, to a lesser extent, its passage

316 through the RO membrane. Both salinity increase in the bioreactor and concentration

317 decrease of the draw solution could reduce the net driving force (i.e. effective trans-

318 membrane osmotic pressure) for water permeation. On day 20 of the experiment, $100 \mathrm{~g} \mathrm{NaCl}$

319 was added to replenish the draw solute loss, which slightly enhanced the water flux (by

320 approximately $1.5 \mathrm{~L} / \mathrm{m}^{2} \mathrm{~h}$ ). Despite the low fouling propensity of the FO membrane, a cake

321 layer was observed on the membrane surface at the conclusion of OMBR operation,

322 predominately consisting of carbon, oxygen, phosphorus, sodium, magnesium, and calcium

323 (Figure S3, Supplementary Data).

324 Water flux of conventional MBR was adjusted daily to match that of OMBR and thus

325 maintain a comparable effluent flux toward the downstream RO process. As a result, the MF

326 membrane was operated at a relatively low water flux, which in turn resulted in negligible

327 membrane fouling as indicated by a small TMP increase throughout conventional MBR

328 operation (Figure S4, Supplementary Data). In practice, the water flux of conventional MBR

329 is usually above $10 \mathrm{~L} / \mathrm{m}^{2} \mathrm{~h}$ (Hai et al., 2014), which is considerably higher than the water flux

$330\left(4-8 \mathrm{~L} / \mathrm{m}^{2} \mathrm{~h}\right)$ used in this study. Although FO is more resistant to fouling compared to

331 UF/MF given the different mechanisms of water transport (i.e. osmotically driven and

332 hydraulic pressure driven for FO and UF/MF, respectively), fouling behaviour and separation

333 performance of FO at a higher flux can differ from those reported here. Nevertheless, with

334 continued progress in membrane development (Fane et al., 2015; Shaffer et al., 2015; Werber 
et al., 2016), fouling resistant, high flux and high separation performance FO membranes can

336 be available in a near future. Indeed, several different research groups have reported new FO

337 membranes with water permeability two to three times higher than that of the commercial

338 membrane used in this study (Tian et al., 2015; Wei et al., 2015). Such progress in membrane

339 fabrication may provide more opportunities in the deployment of OMBR with better

340 contaminant removal and less membrane fouling.

\section{$341 \quad 3.1 .2 \quad$ Biomass characteristics}

342 Salinity build-up in the bioreactor altered biomass characteristics during OMBR operation

343 (Figure 2). A small but discernible decrease in biomass concentration (i.e. MLSS and 344 MLVSS) and SOUR was observed within the first two weeks (Figure 2a-c). This observation 345 is in good agreement with previous studies (Wang et al., 2014; Luo et al., 2015b), and could 346 be ascribed to the inhibition on biomass growth and activity with salinity increase. In 347 addition, the high salinity also increased SMP and EPS concentrations in the mixed liquor 348 (Figure 2d, e), which might be responsible for the FO membrane fouling as discussed above. 349 It has been reported that the elevated salinity could increase the endogenous respiration of 350 microorganisms in activated sludge and thus enhance the secretion of organic cellular 351 substances (Lay et al., 2010; Chen et al., 2014). Nevertheless, biomass concentration and 352 activity recovered gradually from day 14 onward, possibly due to microbial acclimatization 353 to the saline condition, which consequently resulted in the dominance of halotolerant bacteria 354 in the bioreactor (Figures 3 and 4). Meanwhile, SMP and EPS concentrations in the mixed 355 liquor decreased and then stabilized at approximately 20 and $55 \mathrm{mg} / \mathrm{g}$ MLVSS, respectively 356 (Figure 2d, e). 
Biomass growth (indicated by the MLSS and MLVSS concentrations) and activity (indicated by the sludge SOUR) were relatively stable during conventional MBR operation (Figure 2). However, both SMP and EPS concentrations in the mixed liquor decreased significantly, likely due to a reduction in the organic loading rate caused by the decreasing water flux (to match that of OMBR). Given a stable sludge concentration, a decrease in the organic loading rate could lower the ratio of food to microorganism (i.e. F/M), thereby increasing the SMP and EPS biodegradation (Wu et al., 2013).

\subsubsection{Microbial community structure}

366

Sludge samples collected from OMBR and conventional MBR were clustered based on the unweighted Unifrac distance by applying hierarchical clustering (Figure 3). The unweighted Unifrac distance among samples represents the dissimilarity in their microbial communities in a phylogenetic tree. Results show that microbial community structure varied differently in OMBR and conventional MBR (Figures 3 and 4). Sludge samples taken at the beginning of OMBR and conventional MBR operation (i.e. on day 0) formed one cluster, confirming similar microbial communities in these two systems at the initial phase (Figure 3). However, the sludge sample collected at the end of OMBR operation (i.e. on day 40) created a branch distinct from the cluster of other samples. This result indicates that salinity build-up in OMBR significantly impacted the development of the microbial community, rendering it different from that in conventional MBR. In addition, distant clusters were observed for the two sludge samples taken at the beginning and conclusion of conventional MBR operation.

378 This observation could be attributed to microbial variation in response to the prolonging HRT

379 due to continuous water flux decline (Figure 1). It is noteworthy that natural and transient changes in microbial community during MBR operation could also occur (Luo et al., 2016c; Phan et al., 2016). 
384 Further taxonomic analysis revealed significant difference in the microbial community between OMBR and conventional MBR (Figure 3). For instance, the phylum Planctomycetes in conventional MBR was much more abundant than that in OMBR (Figure 4a). This result is consistent with our previous study that showed a decrease in the abundance of the phylum Planctomycetes in a conventional MBR when its influent salinity increased (Luo et al., 2016c). Microbial species of the phylum Bacteroidetes are usually detected in both marine and freshwater environments (Zhang et al., 2013). Thus, the phylum Bacteroidetes was identified in all sludge samples with noticeable abundance (Figure 4a). Nevertheless, the abundance of the phylum Bacteroidetes increased during OMBR operation, which could be further attributed to an increase in the dominance of the family Cytophagaceae (Figure 4b).

394 Abundance of the phylum Proteobacteria varied differently during OMBR and conventional MBR operation, although it was the most abundant phylum in both systems (Figure 4a). As conventional MBR operated, the abundance of the phylum Proteobacteria increased significantly, which was mainly contributed by the dominance of the class $\beta$-proteobacteria. Members of the class $\beta$-proteobacteria are typically dominant in freshwater environment

399 (Zhang et al., 2013). Detailed analysis attributed this class dominance to the predominance of 400 the families Oxalobacteraceae and Comamonadaceae (Figure 4b). By contrast, a small increase in the abundance of the class $\beta$-proteobacteria was observed during OMBR operation, which was only contributed by the dominance of the family Comamonadaceae.

403 Zhang et al. (2013) also reported an increase in the abundance of the class $\beta$-proteobacteria 404 along a salinity gradient of $0.34-6.86 \mathrm{~g} / \mathrm{L} \mathrm{NaCl}$ in a Chinese wetland. These results indicate 405 that some microbes affiliated to the class $\beta$-proteobacteria, such as Comamonadaceae, are 406 salt-tolerant and could proliferate under saline conditions. On the other hand, the abundance 407 of the class $\gamma$-proteobacteria decreased considerably in both systems mainly due to the 
408 decaying of the family Xanthomonadaceae. A similar decrease in both systems also occurred 409 for the family Ellin 6075 belonged to the phylum Acidobacteria.

\subsection{Contaminant removal}

\subsubsection{Removal of bulk organic matter and nutrients}

412 No significant difference between OMBR-RO and conventional MBR-RO was observed

413 regarding overall removal of bulk organic matter (i.e. TOC and TN) (Figure 5) and nutrients

414 (i.e. $\mathrm{NH}_{4}{ }^{+}$and $\mathrm{PO}_{4}{ }^{3-}$ ) (Figure 6). Nevertheless, these contaminants exhibited considerably

415 different fates and transport behaviours in the two hybrid systems. A small increase in TOC

416 concentration in the bioreactor was observed at the beginning of OMBR operation (Figure

417 5a). This observation could be attributed to negative effects of salinity build-up on biomass

418 activity as discussed above and the high rejection of biologically persistent substances by the

419 FO membrane. The high rejection FO membrane resulted in negligible TOC concentration in 420 the draw solution and thus ensured a complete overall removal by OMBR-RO. Given the 421 stable biological treatment and the permeation of non-biodegradable organic substances 422 through the MF membrane, TOC concentration in the bioreactor during conventional MBR 423 operation was less than one-tenth of that in OMBR (Figure 5b). Organic substances that were 424 resistant to conventional MBR treatment were effectively retained by the RO membrane, causing notable TOC accumulation in the MBR effluent reservoir and near complete removal by the whole system.

Without a denitrification step, TN removal by activated sludge is limited and depends mainly on microbial assimilation (Hai et al., 2014). In OMBR-RO operation, the high rejection FO and RO membranes induced a considerable TN accumulation in the bioreactor and the draw 
432 through the FO membrane but were rejected by the RO membrane could accumulate in the 433 draw solution in closed-loop FO-RO systems (e.g. OMBR-RO), and eventually deteriorated

434 the product water quality (Shaffer et al., 2012; D'Haese et al., 2013). As a result, the overall 435 TN removal by OMBR-RO decreased from nearly 100 to $50 \%$ within 40 days (Figure 5c). By 436 contrast, TN concentration in the bioreactor was stable at approximately $30 \mathrm{mg} / \mathrm{L}$ during 437 conventional MBR operation (Figure 5d). Nevertheless, the high rejection RO membrane 438 caused a significant TN build-up in the MBR effluent reservoir, which consequently reduced 439 its overall removal by MBR-RO (from approximately 98 to 40\%).

440 Effective nitrification occurred in both OMBR and conventional MBR systems as manifested 441 by the removal of $\mathrm{NH}_{4}{ }^{+}$in their bioreactors (Figure 6a, b). Nevertheless, ammonia oxidizing 442 bacteria (AOB), which oxidize ammonia to nitrite, were not efficiently detected in all sludge samples (Figure 4). Only nitrite oxidizing bacteria (which oxidize nitrite to nitrate) affiliated to the phylum Nitrospirae were identified at a small abundance (Figure 4a). Similar results were also reported previously and could be attributed to the presence of AOB species that were unidentifiable by 16S rRNA-gene sequencing (Luo et al., 2016c; Phan et al., 2016).

447 Additionally, the effective $\mathrm{NH}_{4}{ }^{+}$removal could also be contributed by ammonia oxidizing 448 archaea, which however, were not targeted by the primers designed in this study.

450 Similar to bulk organic matter (i.e. TOC), a small and transient increase in $\mathrm{NH}_{4}^{+}$ 451 concentration was observed in the bioreactor at the beginning of OMBR operation (Figure 452 6a). Nevertheless, the high rejection FO membrane resulted in negligible $\mathrm{NH}_{4}{ }^{+}$concentration 453 in the draw solution. On the other hand, $\mathrm{NH}_{4}{ }^{+}$concentration in the bioreactor was constantly 454 low during conventional MBR operation. However, the high rejection RO membrane induced 455 a small but discernible $\mathrm{NH}_{4}{ }^{+}$build-up in the MBR effluent reservoir from day 20 onward. 
456 Without chemical precipitation, phosphate removal in activated sludge treatment relies mainly on microbial assimilation, especially by polyphosphate accumulating organisms

458

459

460

461

462

463

464

465

466

467

468

469

470

471

472

473

474

475

476

477

478
(PAOs). PAOs are vulnerable to saline stress and a small osmotic pressure increase within their cells caused by salinity build-up may severely reduce their phosphate accumulating ability (Lay et al., 2010; Yogalakshmi, 2010). Nevertheless, the FO membrane can almost completely retain phosphate ions as they are negatively charged and have large hydrated radius (Holloway et al., 2007). As a result, $\mathrm{PO}_{4}{ }^{3-}$ accumulated considerably in the bioreactor while its presence in the draw solution was negligible during OMBR-RO operation (Figure 6c). On the other hand, phosphate could permeate through the MF but not the RO membrane. Thus, phosphate build-up in the MBR effluent reservoir was observed during conventional MBR-RO operation (Figure 6d). It is noteworthy that $\mathrm{PO}_{4}{ }^{3-}$ concentration in the bioreactor was slightly higher than that in influent during conventional MBR operation, possibly owing to its retention by the dynamic fouling layer formed on the MF membrane surface and/or phosphate release from unmetabolized substrates (Yogalakshmi, 2010).

\subsubsection{Removal of trace organic contaminants}

All 31 TrOCs investigated were almost completely removed by both OMBR-RO and conventional MBR-RO (Figure 6), due to the synergy of biological treatment and physical membrane rejection. Nevertheless, removal behaviours of these TrOCs were significantly different in these two hybrid systems, depending on their physiochemical properties, including hydrophobicity and molecular structure (Table S1, Supplementary Data). Of the 31 TrOCs investigated, 18 compounds were hydrophilic (i.e. Log D < 3.2) and 13 compounds were hydrophobic (i.e. $\log \mathrm{D}>3.2)$ (Section 2.1).

[Figure 7] 
479 All 13 hydrophobic TrOCs were biologically removed by over $90 \%$ in both systems (Figure

480 7). Compared to conventional MBR, salinity build-up in the bioreactor did not significantly

481 affect the biological removal of these hydrophobic compounds during OMBR operation.

482 Their high removal by activated sludge has also been demonstrated in several previous

483 studies (Tadkaew et al., 2011; Wijekoon et al., 2013) and can be ascribed to their adsorption

484 onto sludge, which facilitated their biodegradation. Results reported here are also consistent

485 with a previous study by Luo et al. (2015b) who reported insignificant variation in the

486 removal of hydrophobic TrOCs by conventional MBR as the mixed liquor salinity increased

487 (up to $16.5 \mathrm{~g} / \mathrm{L} \mathrm{NaCl}$ ). The effective removal of hydrophobic TrOCs by activated sludge

488 could consequently reduce their permeation through the FO and subsequent RO membranes,

489 leading to near complete removal by both hybrid systems (Figure 7). It has been reported that

490 an initial adsorption but subsequent partition and diffusion of hydrophobic TrOCs

491 (particularly, non-ionic compounds) through membranes could reduce their rejection in a

492 stand-alone FO or RO process (Nghiem and Coleman, 2008; Xie et al., 2014).

493 Varying removal rates of hydrophilic TrOCs were observed in both bioreactors (Figure 7).

494 Effective removal (> 90\%) was observed for several hydrophilic compounds, including

495 salicylic acid, ketoprofen, naproxen, metronidazole, ibuprofen, gemfibrozil, enterolactone,

496 pentachlorophenol, DEET, and estriol. This result can be attributed to the high

497 biodegradability of these compounds, whose molecular structures have strong electron

498 donating functional groups (e.g. amine and hydroxyl) (Tadkaew et al., 2011). On the other

499 hand, some hydrophilic TrOCs were poorly removed in both bioreactors, with removal rates

500 only in the range of $20-70 \%$. They included clofibric acid, fenoprop, primidone, diclofenac,

501 carbamazepine, atrazine, and ametryn, which are well-known biologically resistant

502 substrates. Their resistance to biological treatment mainly resulted from the presence of

503 strong electron withdrawing functional groups (such as chloride, amide, and nitro) or the lack 
504 of strong electron donating functional groups in their molecular structures (Tadkaew et al., 2011; Wijekoon et al., 2013).

506 Despite the low removal of biologically persistent TrOCs by activated sludge, the high

507 rejection FO membrane prevented their permeation into the draw solution and allowed almost

508 complete removal by OMBR (Figure 7a). A small but nevertheless discernible contribution

509 by the downstream RO membrane was only observed for atrazine and ametryn, which were

510 slightly permeable through the FO membrane. Our results are consistent with previous

511 studies which demonstrated excellent removal of TrOCs by FO or FO-RO (Hancock et al.,

512 2011; D'Haese et al., 2013; Alturki et al., 2013). On the other hand, conventional MBR could

513 not effectively remove these biologically persistent TrOCs although the dynamic fouling

514 layer formed on the MF membrane surface rejected them to some extent (Figure $7 \mathrm{~b}$ ).

515 Nevertheless, the high rejection RO membrane complemented well to MBR for the high

516 overall removal of these compounds.

\section{$517 \quad 3.3 \quad$ Reverse osmosis membrane fouling}

518 Water flux of the RO process subsequent to conventional MBR was adjusted daily to match

519 that of the RO process subsequent to OMBR (Section 2.3). Changes in the applied hydraulic

520 pressures to the RO membrane in these two hybrid systems are shown in Figure 8a. To

521 compare fouling development on the RO membrane surface, the normalized water permeability was also determined (Figure $8 b$ ), which is the ratio of the effective membrane water permeability to the initial value $\left(P / P_{0}\right)$.

\section{[Figure 8]}

525 The normalized water permeability of the RO membrane decreased less significantly than in

526 conventional MBR-RO (Figure 8). This result indicates that the RO membrane fouling was more severe when treating conventional MBR effluent compared to reconcentrating the 
528 OMBR draw solution due to their different water qualities and foulant contents (Figures 5 529 and 6). Thus, although the RO membrane in OMBR-RO was operated at a higher initial 530 hydraulic pressure to overcome the osmotic pressure of the draw solution (i.e. $0.5 \mathrm{M} \mathrm{NaCl}$ ), 531 the hydraulic pressure applied to the RO membrane in conventional MBR-RO increased 532 much more rapidly and frequent RO membrane replacement was needed to match the water 533 flux of OMBR-RO (Figure 8a). Severe RO membrane fouling observed in conventional 534 MBR-RO can be attributed to foulant accumulation in the MBR effluent reservoir. Indeed, EEM analysis revealed foulant build-up, such as humic-like $\left(\lambda_{\text {ex/em }}=300-370 / 400-500 \mathrm{~nm}\right)$ and protein-like substances $\left(\lambda_{\mathrm{ex} / \mathrm{em}}=275-290 / 330-370 \mathrm{~nm}\right)$, in the MBR effluent (Figure S5, 537 Supplementary Data).

538 The FO process effectively prevented foulants from permeating into the draw solution

539 (Figures 6 and 7), thereby reducing membrane fouling in the downstream RO process. For 540 instance, the humic- and protein-like substances accumulated considerably in the bioreactor, 541 but their presence in the draw solution was negligible (Figure S5, Supplementary Data). 542 However, the RO normalized water permeability decreased gradually and stabilized at 543 approximately 0.35 from day 20 onward during OMBR-RO operation (Figure 8b). The 544 observed permeability decline could be attributed to membrane compaction (particularly within the first week of operation) and fouling under the high hydraulic pressure (Figure 8a).

546 The fouling layer on the RO membrane surface exhibited different morphologies in OMBR547 RO and conventional MBR-RO (Figure 9a, b). Foulant clusters were sparsely distributed 548 without forming a dense fouling layer on the RO membrane surface subsequent to OMBR 549 (Figure 9a). Elementary analysis by EDS revealed that these clusters comprised carbon, 550 oxygen, sodium, and chloride (Figure 9c). By contrast, a compact and homogenous cake 551 layer formed on the RO membrane surface in conventional MBR-RO (Figure 9b), 552 predominantly containing carbon, oxygen, magnesium, calcium, and phosphate (Figure 9d). 
553 This result indicates the formation of both organic and inorganic membrane fouling. However,

554 regularly shaped or needle-like crystals typically formed with inorganic scaling were not

555 visualized on the RO membrane surface subsequent to conventional MBR although

556 magnesium, calcium, and phosphate were detected (Figure 9b). This result was possibly due

557 to the formation of inorganic precipitates in the organic fouling layer or the complexation

558 between these divalent cations and organic molecules (e.g. protein-like substances) on the 559 membrane surface (Zhao et al., 2010).

[Figure 9]

561 Organic fouling layer on the RO membrane surface was characterized by ATR-FTIR

562 measurement (Figure 10). The pristine RO membrane showed typical absorbance peaks at 563 wavenumbers of $3345 \mathrm{~cm}^{-1}$ (N-H stretching), $3300 \mathrm{~cm}^{-1}$ (O-H stretching), $1671 \mathrm{~cm}^{-1}$ (strong 564 amide $\mathrm{C}=\mathrm{O}), 2946$ and $1487 \mathrm{~cm}^{-1}\left(\mathrm{C}-\mathrm{H}\right.$ stretching), and $1168 \mathrm{~cm}^{-1}$ (amide ring). Similar ATR565 FTIR spectra were also observed for the RO membrane coupled with OMBR, confirming the 566 formation of slight and scattered organic fouling layer on the membrane surface. By contrast, 567 the RO membrane subsequent to conventional MBR exhibited distinctive adsorption peaks at $5681653 \mathrm{~cm}^{-1}$, which usually associates with alkene $(\mathrm{C}=\mathrm{C})$ in aliphatic structures and/or amide I $569(\mathrm{C}=\mathrm{O})$ bonds, and at $1543 \mathrm{~cm}^{-1}$, representing amide II $(\mathrm{C}-\mathrm{N}-\mathrm{H})$ bonds. In addition, the fouled 570 RO membrane also showed a sharp peak at $1032 \mathrm{~cm}^{-1}$, indicating carbonyl $(\mathrm{C}=\mathrm{O})$ bonds of 571 polysaccharides. These results suggest that humic- and protein-like substances accumulated 572 in the MBR effluent were likely responsible for the severe organic fouling of the RO 573 membrane in conventional MBR-RO. 
576 High product water quality and low membrane fouling imply robustness of OMBR-RO in

577 advanced wastewater treatment and water reuse. Results reported here highlight the benefits of OMBR-RO over conventional MBR-RO. Compared to conventional MBR-RO, the high rejection FO membrane prevents the downstream RO process from severe membrane fouling, thereby reducing membrane cleaning and maintenance during OMBR-RO operation. Moreover, OMBR-RO has the potential to simultaneously achieve seawater desalination and wastewater recycling when seawater is used as the draw solution in coastal regions. By virtue of osmotic dilution, low pressure RO systems can be coupled with OMBR to remove the need for concentrate disposal, thereby reducing energy consumption for seawater desalination and wastewater recovery (Valladares Linares et al., 2016). several strategies to mitigate salinity build-up in OMBR have been proposed, for example, by using organic draw solutions (Luo et al., 2016a) and integrating with the MF/UF membrane for salt bleeding (Holloway et al., 2015; Luo et al., 2016b).

Sludge produced by OMBR is expected to be saline. Thus, further study is necessary to quantify the impact of salinity on subsequent sludge treatment and available sludge reuse options.

\section{Conclusion}

Results reported here show that both OMBR-RO and conventional MBR-RO systems can effectively remove bulk organic matter, nutrients, and all 31 TrOCs investigated. Nevertheless, salinity build-up in the bioreactor reduced the water flux and adversely impacted biological stability by altering biomass characteristics and microbial community structure during OMBR operation. Salinity increase also resulted in more SMP and EPS in the mixed liquor, inducing the FO membrane fouling. With the succession of halophobic 
599 bacteria by halotolerant ones, the OMBR system remained biologically active. Moreover, the

600 high rejection of foulants by the FO membrane prevented the downstream RO process from

601 severe membrane fouling. In contrast to biological variation in OMBR, biological

602 performance was relatively stable during conventional MBR operation. However, foulants

603 (e.g. humic- and protein-like matters and inorganic salts) accumulated considerably in the

604 MBR effluent reservoir, resulting in severe fouling to the subsequent RO membrane.

\section{5. References}

606 Achilli, A., Cath, T.Y., Marchand, E.A., Childress, A.E., 2009. The forward osmosis

607 membrane bioreactor: A low fouling alternative to MBR processes. Desalination 239, 10-

60821.

609 Al Ashhab, A., Herzberg, M., Gillor, O., 2014. Biofouling of reverse-osmosis membranes 610 during tertiary wastewater desalination: Microbial community composition. Water Res. $61150,341-349$.

612 Alturki, A.A., McDonald, J., Khan, S.J., Hai, F.I., Price, W.E., Nghiem, L.D., 2012.

613 Performance of a novel osmotic membrane bioreactor (OMBR) system: Flux stability and 614 removal of trace organics. Bioresour. Technol. 113, 201-206.

615 Alturki, A.A., McDonald, J.A., Khan, S.J., Price, W.E., Nghiem, L.D., Elimelech, M., 2013. 616 Removal of trace organic contaminants by the forward osmosis process. Sep. Purif. 617 Technol. 103, 258-266.

618 Alturki, A.A., Tadkaew, N., McDonald, J.A., Khan, S.J., Price, W.E., Nghiem, L.D., 2010.

619 Combining MBR and NF/RO membrane filtration for the removal of trace organics in 620 indirect potable water reuse applications. J. Membr. Sci. 365, 206-215.

621 APHA. 2005. Standard methods for the examination of water and wastewater. APHA622 AWWA-WEF. 9780875530475, 0875530478. 
623 Caporaso, J.G., Kuczynski, J., Stombaugh, J., Bittinger, K., Bushman, F.D., Costello, E.K., 624 Fierer, N., Peña, A.G., Goodrich, J.K., Gordon, J.I., Huttley, G.A., Kelley, S.T., Knights, 625 D., Koenig, J.E., Ley, R.E., Lozupone, C.A., McDonald, D., Muegge, B.D., Pirrung, M., 626 Reeder, J., Sevinsky, J.R., Turnbaugh, P.J., Walters, W.A., Widmann, J., Yatsunenko, T., 627 Zaneveld, J., Knight, R., 2010. QIIME allows analysis of high-throughput community 628 sequencing data. Nat. Methods 7, 335-336.

629 Cath, T.Y., Hancock, N.T., Lampi, J., Nghiem, L.D., Xie, M., Yip, N.Y., Elimelech, M., 630 McCutcheon, J.R., McGinnis, R.L., Achilli, A., Anastasio, D., Brady, A.R., Childress, 631 A.E., Farr, I.V., 2013. Standard methodology for evaluating membrane performance in 632 osmotically driven membrane processes. Desalination 312, 31-38.

633 Chen, L., Gu, Y., Cao, C., Zhang, J., Ng, J.-W., Tang, C., 2014. Performance of a submerged anaerobic membrane bioreactor with forward osmosis membrane for low-strength wastewater treatment. Water Res. 50, 114-123.

636

Clara, M., Strenn, B., Gans, O., Martinez, E., Kreuzinger, N., Kroiss, H., 2005. Removal of selected pharmaceuticals, fragrances and endocrine disrupting compounds in a membrane bioreactor and conventional wastewater treatment plants. Water Res. 39, 4797-4807.

Cornelissen, E.R., Harmsen, D., Beerendonk, E.F., Qin, J.J., Oo, H., De Korte, K.F., 640 Kappelhof, J.W.M.N., 2011. The innovative osmotic membrane bioreactor (OMBR) for 641 reuse of wastewater. Water Sci. Technol. 63, 1557-1565.

642 Cory, R.M., McKnight, D.M., 2005. Fluorescence spectroscopy reveals ubiquitous presence 643 of oxidized and reduced quinones in dissolved organic matter. Environ. Sci. Technol. 39, 644 8142-8149.

645 D'Haese, A., Le-Clech, P., Van Nevel, S., Verbeken, K., Cornelissen, E.R., Khan, S.J., 646 Verliefde, A.R.D., 2013. Trace organic solutes in closed-loop forward osmosis 
applications: Influence of membrane fouling and modeling of solute build-up. Water Res. $47,5232-5244$.

649

De Wever, H., Weiss, S., Reemtsma, T., Vereecken, J., Müller, J., Knepper, T., Rörden, O., Gonzalez, S., Barcelo, D., Dolores Hernando, M., 2007. Comparison of sulfonated and other micropollutants removal in membrane bioreactor and conventional wastewater treatment. Water Res. 41, 935-945.

653

Edgar, R.C., 2013. UPARSE: Highly accurate OTU sequences from microbial amplicon 654 reads. Nat. Methods 10, 996-998.

655

Elimelech, M., Phillip, W.A., 2011. The future of seawater desalination: Energy, technology, and the environment. Science 333, 712-717.

Fane, A.G., Wang, R., Hu, M.X., 2015. Synthetic Membranes for Water Purification: Status and Future. Angew. Chem. Int. Ed.

659

Farias, E.L., Howe, K.J., Thomson, B.M., 2014. Effect of membrane bioreactor solids retention time on reverse osmosis membrane fouling for wastewater reuse. Water Res. 49,

661 53-61.

662

Gerrity, D., Pecson, B., Trussell, R.S., Trussell, R.R., 2013. Potable reuse treatment trains 663 throughout the world. J. Water Supply Res. Technol. AQUA 62, 321-338.

664

Hai, F.I., Tessmer, K., Nguyen, L.N., Kang, J., Price, W.E., Nghiem, L.D., 2011. Removal of 665 micropollutants by membrane bioreactor under temperature variation. J. Membr. Sci. 383,

Hai, F.I., Yamamoto, K., Lee, C.H. 2014. Membrane Biological Reactors: Theory, Modeling, Design, Management and Applications to Wastewater Reuse. IWA Publishing, London. pilot-scale investigation of trace organic compounds rejection by forward osmosis. Environ. Sci. Technol. 45, 8483-8490. 
672 Henderson, R.K., Baker, A., Murphy, K.R., Hambly, A., Stuetz, R.M., Khan, S.J., 2009.

673 Fluorescence as a potential monitoring tool for recycled water systems: A review. Water $674 \quad$ Research 43, 863-881.

675 Holloway, R.W., Childress, A.E., Dennett, K.E., Cath, T.Y., 2007. Forward osmosis for 676 concentration of anaerobic digester centrate. Water Res. 41, 4005-4014.

677 Holloway, R.W., Regnery, J., Nghiem, L.D., Cath, T.Y., 2014. Removal of trace organic 678 chemicals and performance of a novel hybrid ultrafiltration-osmotic membrane 679 bioreactor. Environ. Sci. Technol. 48, 10859-10868.

680 Holloway, R.W., Wait, A.S., Da Silva, A.F., Herron, J., Schutter, M.D., Lampi, K., Cath, 681 T.Y., 2015. Long-term pilot scale investigation of novel hybrid ultrafiltration-osmotic 682 membrane bioreactors. Desalination 363, 64.

683 Kim, Y., Elimelech, M., Shon, H.K., Hong, S., 2014. Combined organic and colloidal fouling 684 in forward osmosis: Fouling reversibility and the role of applied pressure. J. Membr. Sci. $685 \quad 460,206-212$.

686 Lay, W.C.L., Liu, Y., Fane, A.G., 2010. Impacts of salinity on the performance of high 687 retention membrane bioreactors for water reclamation: A review. Water Res. 44, 21-40.

688 Lu, X., Ma, J., Nejati, S., Choo, Y., Osuji, C.O., Elimelech, M., 2015. Elements provide a 689 clue: Nanoscale characterization of thin-film composite polyamide membranes. ACS 690 Appl. Mater. Interfaces 7, 16917-16922.

691 Luo, W., Hai, F.I., Price, W.E., Elimelech, M., Nghiem, L.D., 2016a. Evaluating ionic 692 organic draw solutes in osmotic membrane bioreactors for water reuse. J. Membr. Sci. $693 \quad 514,636-645$.

694 Luo, W., Hai, F.I., Price, W.E., Guo, W., Ngo, H.H., Yamamoto, K., Nghiem, L.D., 2014a. 695 High retention membrane bioreactors: Challenges and opportunities. Bioresour. Technol. $696 \quad 167,539-546$. 
697 Luo, W., Hai, F.I., Price, W.E., Guo, W., Ngo, H.H., Yamamoto, K., Nghiem, L.D., $2016 b$.

698 Phosphorus and water recovery by a novel osmotic membrane bioreactor-reverse osmosis

$699 \quad$ system. Bioresour. Technol. 200, 297-304.

700 Luo, W., Hai, F.I., Price, W.E., Nghiem, L.D., 2015a. Water extraction from mixed liquor of 701 an aerobic bioreactor by forward osmosis: Membrane fouling and biomass characteristics 702 assessment. Sep. Purif. Technol. 145, 56-62.

703 Luo, W., Phan, H.V., Hai, F.I., Price, W.E., Guo, W., Ngo, H.H., Yamamoto, K., Nghiem,

704 L.D., 2016c. Effects of salinity build-up on the performance and bacterial community 705 structure of a membrane bioreactor. Bioresour. Technol. 200, 305-310.

706 Luo, W.H., Hai, F.I., Kang, J.G., Price, W.E., Guo, W.S., Ngo, H.H., Yamamoto, K., 707 Nghiem, L.D., 2015b. Effects of salinity build-up on biomass characteristics and trace 708 organic chemical removal: Implications on the development of high retention membrane 709 bioreactors. Bioresour. Technol. 177, 274-281.

710 Luo, Y.L., Guo, W.S., Ngo, H.H., Nghiem, L.D., Hai, F.I., Zhang, J., Liang, S., Wang, 711 X.C.C., 2014b. A review on the occurrence of micropollutants in the aquatic environment 712 and their fate and removal during wastewater treatment. Sci. Total Environ. 473, 619-641.

713 Mi, B., Elimelech, M., 2010. Organic fouling of forward osmosis membranes: Fouling 714 reversibility and cleaning without chemical reagents. J. Membr. Sci. 348, 337-345.

715 Nghiem, L.D., Coleman, P.J., 2008. NF/RO filtration of the hydrophobic ionogenic 716 compound triclosan: Transport mechanisms and the influence of membrane fouling. Sep. 717 Purif. Technol. 62, 709-716.

718 Nguyen, L.N., Hai, F.I., Kang, J., Price, W.E., Nghiem, L.D., 2013. Removal of emerging 719 trace organic contaminants by MBR-based hybrid treatment processes. Int. Biodeterior. $720 \quad$ Biodegrad. 85, 474-482. 
Nguyen, N.C., Chen, S.-S., Nguyen, H.T., Ray, S.S., Ngo, H.H., Guo, W., Lin, P.-H., 2016. Innovative sponge-based moving bed-osmotic membrane bioreactor hybrid system using a new class of draw solution for municipal wastewater treatment. Water Res. 91, 305-313.

Phan, H.V., Hai, F.I., Zhang, R., Kang, J., Price, W.E., Nghiem, L.D., 2016. Bacterial community dynamics in an anoxic-aerobic membrane bioreactor - Impact on nutrient and trace organic contaminant removal. Int. Biodeterior. Biodegrad. 109, 61-72.

Semblante, G.U., Hai, F.I., Bustamante, H., Guevara, N., Price, W.E., Nghiem, L.D., 2015. Effects of iron salt addition on biosolids reduction by oxic-settling-anoxic (OSA) process. Int. Biodeterior. Biodegrad. 104, 391-400.

Shaffer, D.L., Werber, J.R., Jaramillo, H., Lin, S., Elimelech, M., 2015. Forward osmosis: Where are we now? Desalination 356, 271-284.

Shaffer, D.L., Yip, N.Y., Gilron, J., Elimelech, M., 2012. Seawater desalination for agriculture by integrated forward and reverse osmosis: Improved product water quality for potentially less energy. J. Membr. Sci. 415-416, 1-8.

Tadkaew, N., Hai, F.I., McDonald, J.A., Khan, S.J., Nghiem, L.D., 2011. Removal of trace organics by MBR treatment: The role of molecular properties. Water Res. 45, 2439-2451.

Tian, M., Wang, Y.-N., Wang, R., 2015. Synthesis and characterization of novel highperformance thin film nanocomposite (TFN) FO membranes with nanofibrous substrate reinforced by functionalized carbon nanotubes. Desalination 370, 79-86.

Valladares Linares, R., Li, Z., Yangali-Quintanilla, V., Ghaffour, N., Amy, G., Leiknes, T., Vrouwenvelder, J.S., 2016. Life cycle cost of a hybrid forward osmosis - low pressure reverse osmosis system for seawater desalination and wastewater recovery. Water Res. $88,225-234$. 
744 Wang, X.H., Yuan, B., Chen, Y., Li, X.F., Ren, Y.P., 2014. Integration of micro-filtration 745 into osmotic membrane bioreactors to prevent salinity build-up. Bioresour. Technol. 167, $746 \quad 116-123$

747 Wei, R., Zhang, S., Cui, Y., Ong, R.C., Chung, T.-S., Helmer, B.J., de Wit, J.S., 2015. Highly 748 permeable forward osmosis (FO) membranes for high osmotic pressure but viscous draw 749 solutes. J. Membr. Sci. 496, 132-141.

750 Werber, J.R., Osuji, C.O., Elimelech, M., 2016. Materials for next-generation desalination $751 \quad$ and water purification membranes. Nat. Rev. Mater. 1, 16018.

752 Wijekoon, K.C., Hai, F.I., Kang, J., Price, W.E., Guo, W., Ngo, H.H., Nghiem, L.D., 2013. The fate of pharmaceuticals, steroid hormones, phytoestrogens, UV-filters and pesticides during MBR treatment. Bioresour. Technol. 144, 247-254.

Wu, B., Kitade, T., Chong, T.H., Lee, J.Y., Uemura, T., Fane, A.G., 2013. Flux-dependent 756 fouling phenomena in membrane bioreactors under different food to microorganisms (F/M) ratios. Sep. Sci. Technol. 48, 840-848.

Xie, M., Gray, S.R., 2016. Transport and accumulation of organic matter in forward osmosisreverse osmosis hybrid system: Mechanism and implications. Sep. Purif. Technol. 167, 616.

761

Xie, M., Lee, J., Elimelech, M., Nghiem, L.D., 2015. Role of pressure in organic fouling in forward osmosis and reverse osmosis. J. Membr. Sci. 493, 748-754.

Xie, M., Nghiem, L.D., Price, W.E., Elimelech, M., 2014. Relating rejection of trace organic contaminants to membrane properties in forward osmosis: Measurements, modelling and implications. Water Res. 49, 265-274.

766 Yogalakshmi, K.N., 2010. Effect of transient sodium chloride shock loads on the performance of submerged membrane bioreactor. Bioresour. Technol. 101, 7054-7061. 
768 Zhang, J.J., Kobert, K., Flouri, T., Stamatakis, A., 2014. PEAR: a fast and accurate Illumina 769 Paired-End reAd mergeR. Bioinformatics 30, 614-620.

770 Zhang, L., Gao, G., Tang, X., Shao, K., Bayartu, S., Dai, J., 2013. Bacterial community 771 changes along a salinity gradient in a Chinese wetland. Can. J. Microbiol. 59, 611-619.

772 Zhang, X., Bishop, P.L., Kinkle, B.K., 1999. Comparison of extraction methods for 773 quantifying extracellular polymers in biofilms. Water Sci. Technol. 39, 211-218.

774 Zhao, Y., Song, L., Ong, S.L., 2010. Fouling behavior and foulant characteristics of reverse 775 osmosis membranes for treated secondary effluent reclamation. J. Membr. Sci. 349, 65776 74. 


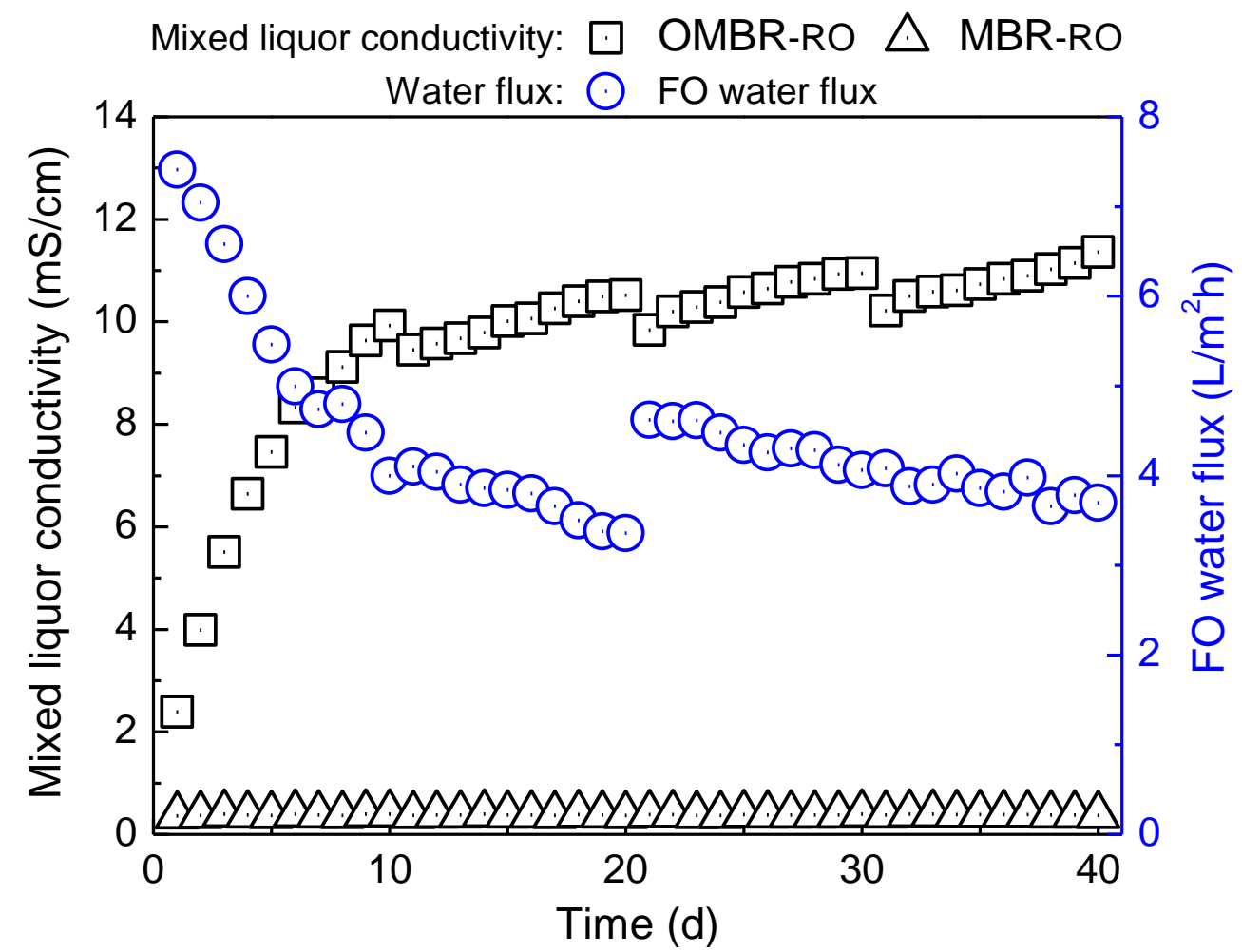

778

Figure 1: Mixed liquor electrical conductivity and FO water flux during OMBR-RO and conventional MBR-RO operation. MF (used in conventional MBR) and RO water fluxes were adjusted daily to match that of FO. The MF membrane was operated in a cycle of 14

$782 \mathrm{~min}$ on and $1 \mathrm{~min}$ off. Experimental conditions: DO $=5 \mathrm{mg} / \mathrm{L}$; initial MLSS = $5.5 \mathrm{~g} / \mathrm{L}$; HRT

$783=27-60 \mathrm{~h} ; \mathrm{SRT}=20 \mathrm{~d}$; temperature $=22 \pm 1{ }^{\circ} \mathrm{C}$; initial $\mathrm{FO}$ draw solution $=0.5 \mathrm{M} \mathrm{NaCl}$;

784 draw cross-flow velocity $=2.8 \mathrm{~cm} / \mathrm{s} ;$ RO cross-flow velocity $=41.5 \mathrm{~cm} / \mathrm{s}$. On day $20,100 \mathrm{~g}$

$785 \mathrm{NaCl}$ was added to OMBR draw solution (with constant working volume of $10 \mathrm{~L}$ ) to 786 replenish draw solute loss. 

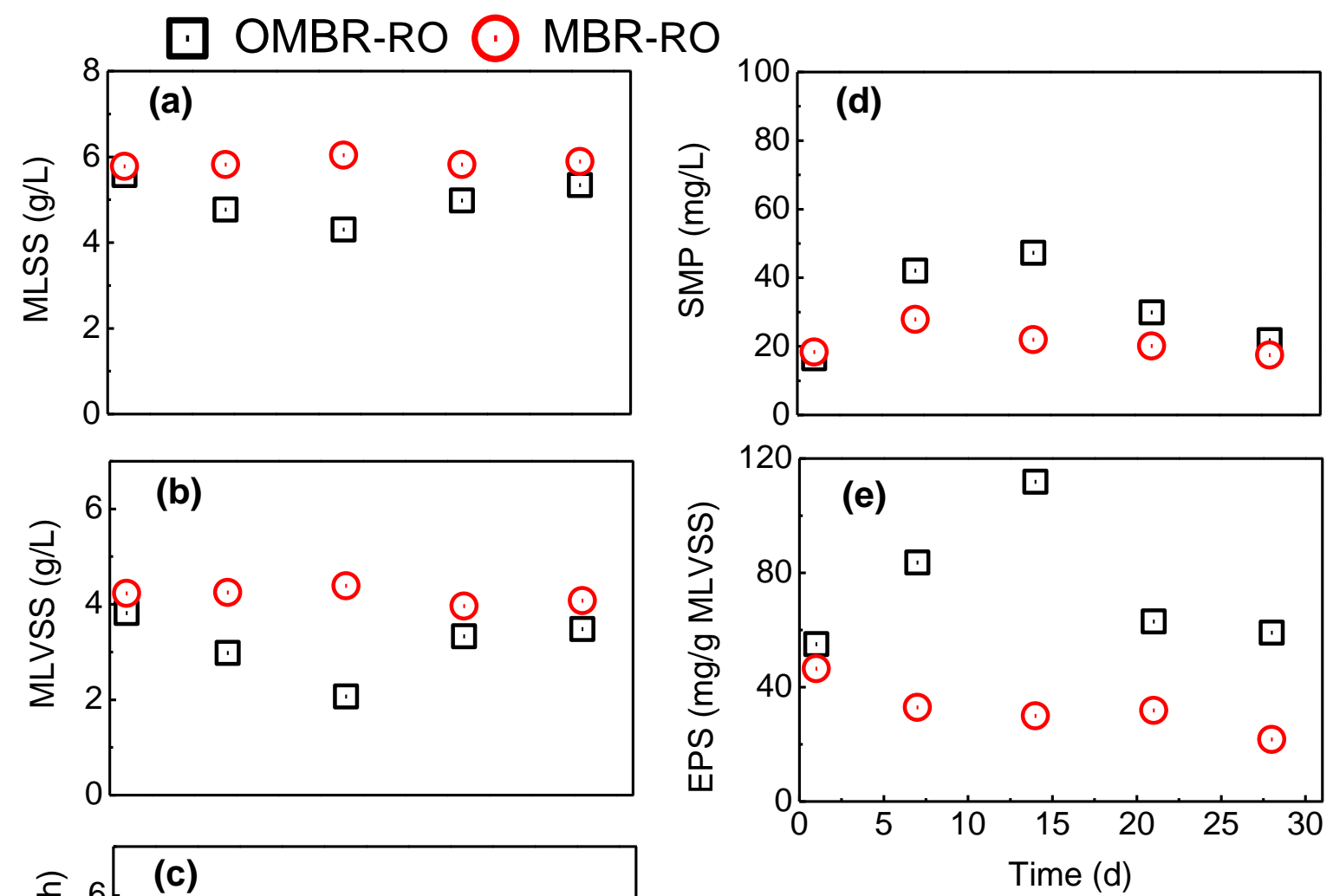

787

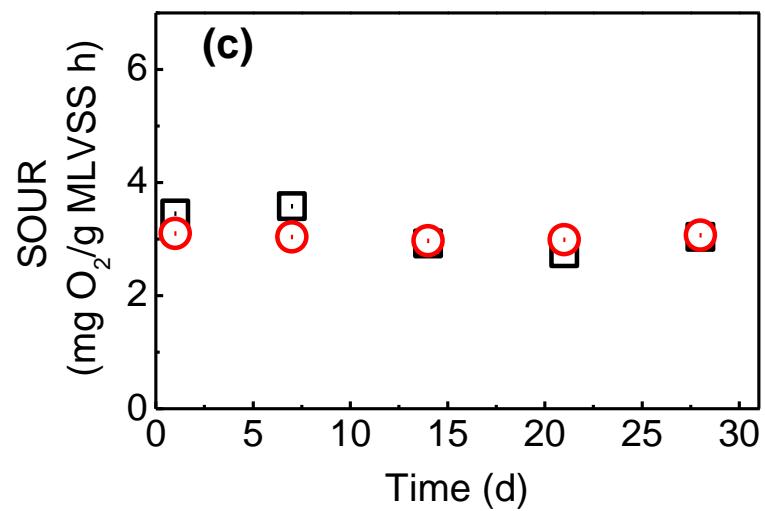

788 Figure 2: Key biomass characteristics during OMBR-RO and conventional MBR-RO 789 operation. 
MBR-RO (40 d)

MBR-RO (0 d)

OMBR-RO (0 d)

790

OMBR-RO (40 d)

791 Figure 3: Hierarchical clustering based on the unweighted UniFrac metric. The branch length

792 represents the distance (indicated by scale bar) among bacterial communities of sludge

793 samples in UniFrac units. Labels on the branch indicate sludge samples collected from

794 bioreactors at the beginning (0 day) and conclusion (40 day) of OMBR-RO and conventional

795 MBR-RO operation. Experimental conditions are as described in the caption of Figure 1. 

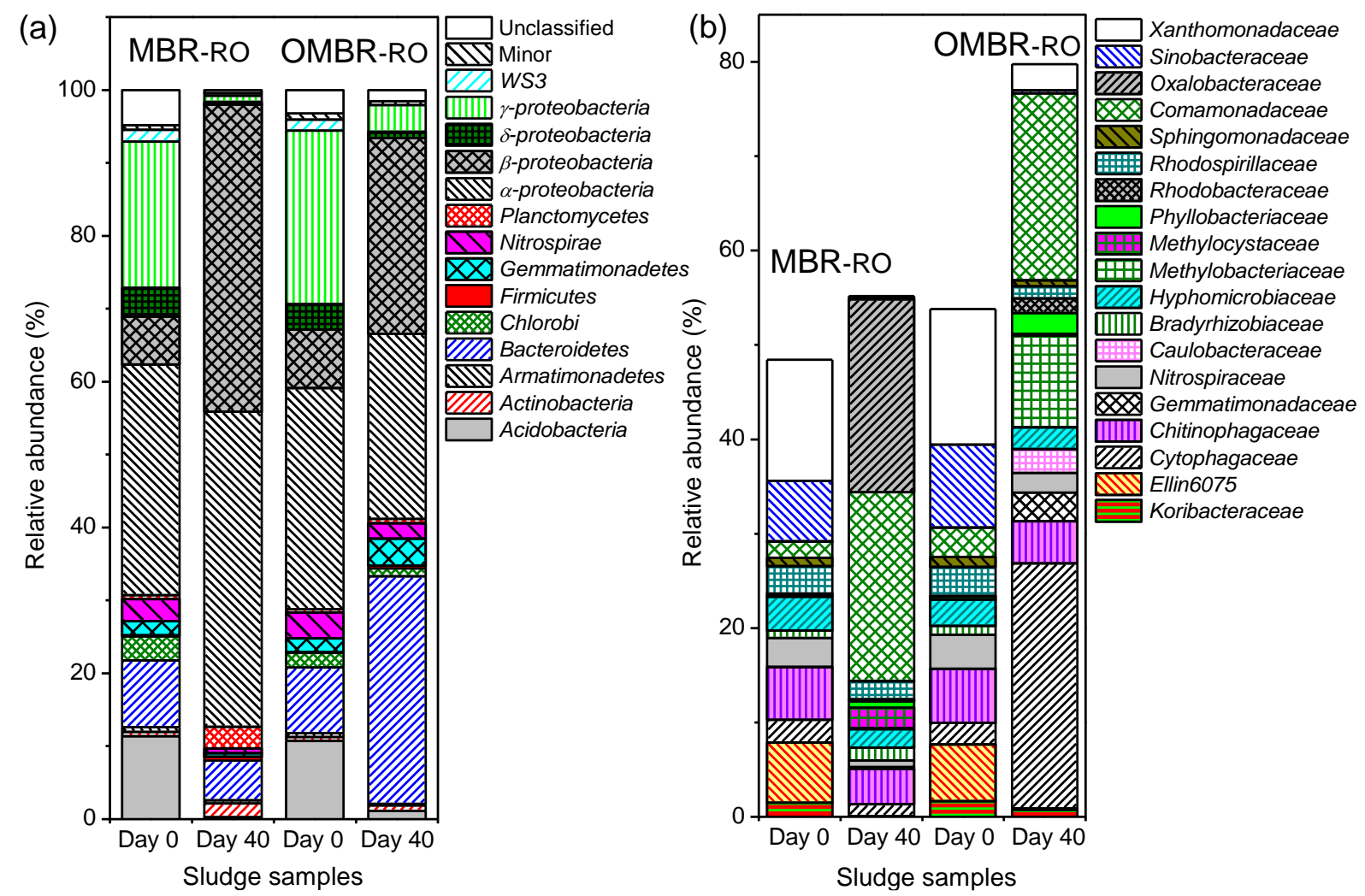

Figure 4: Relative abundance of dominant (a) phyla and (b) families (>1\%) in sludge 799 samples collected from bioreactors at the beginning (day 0) and conclusion (day 40) of 800 OMBR-RO and conventional MBR-RO operation. The phylum Proteobacteria comprised the 801 classes $\alpha-, \beta$-, $\delta$ - and $\gamma$-proteobacteria. Phyla with relative abundance $<0.5 \%$ were grouped 802 as "Minor". 
$\neg-$ Feed $-\triangle$ Bioreactor $-\mathrm{O}-$ Draw solution $-4-$ MBR effluent - RO permeate - Removal

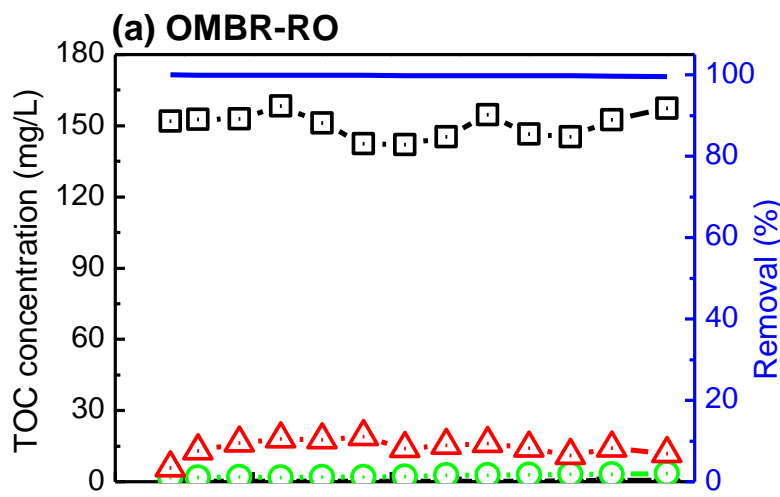

(b) MBR-RO
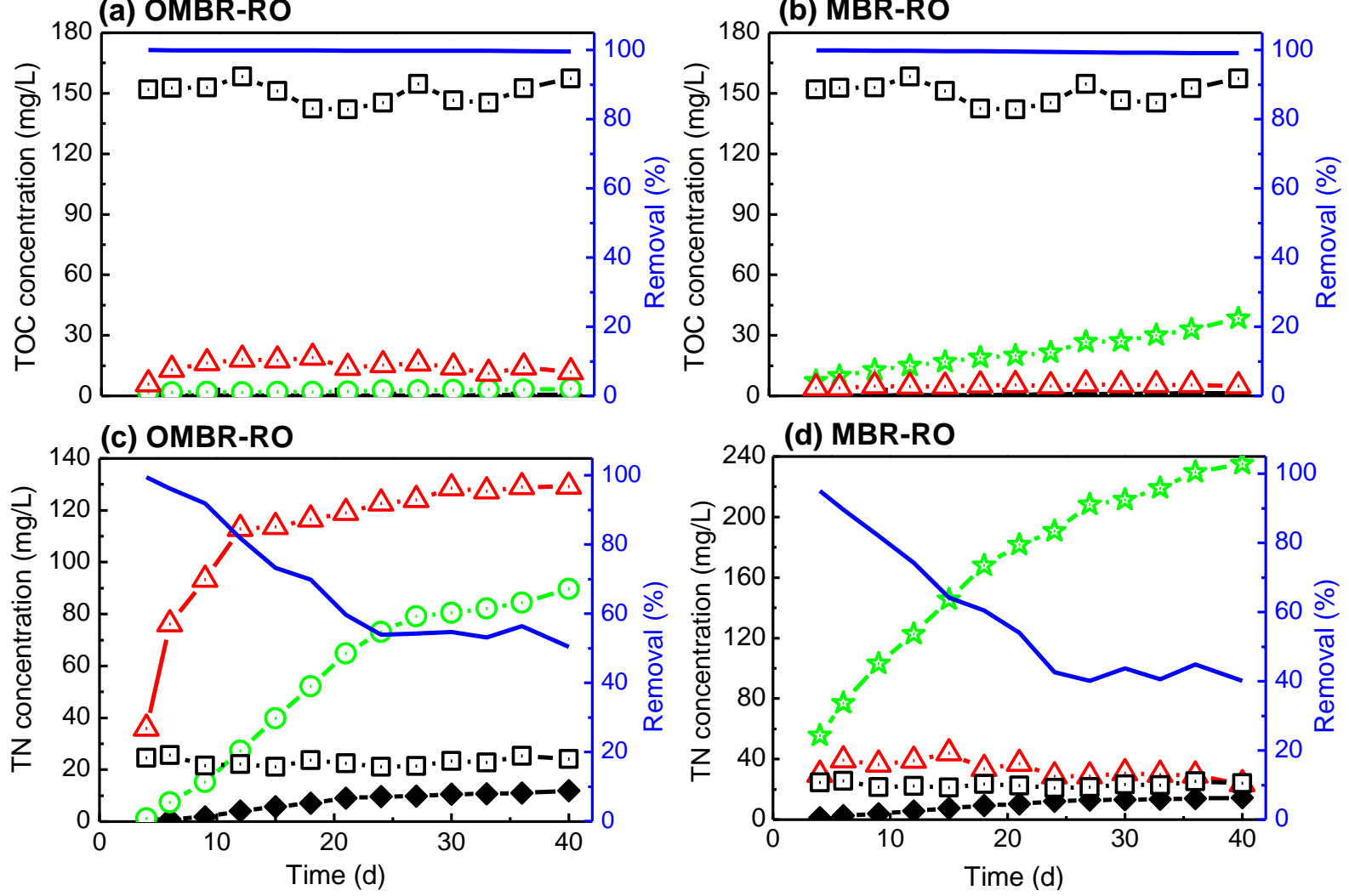

803

Figure 5: $\mathrm{TOC}$ and $\mathrm{TN}$ concentrations and removal rates during OMBR-RO and

805 conventional MBR-RO operation. The two systems were operated under the same conditions

806 as described in the caption of Figure 1.

807 
$\neg-$ Feed $-\triangle$ Bioreactor $-\bigcirc-$ Draw solution $\triangle-$ MBR effluent $\neg$ RO permeate $\longrightarrow$ Removal
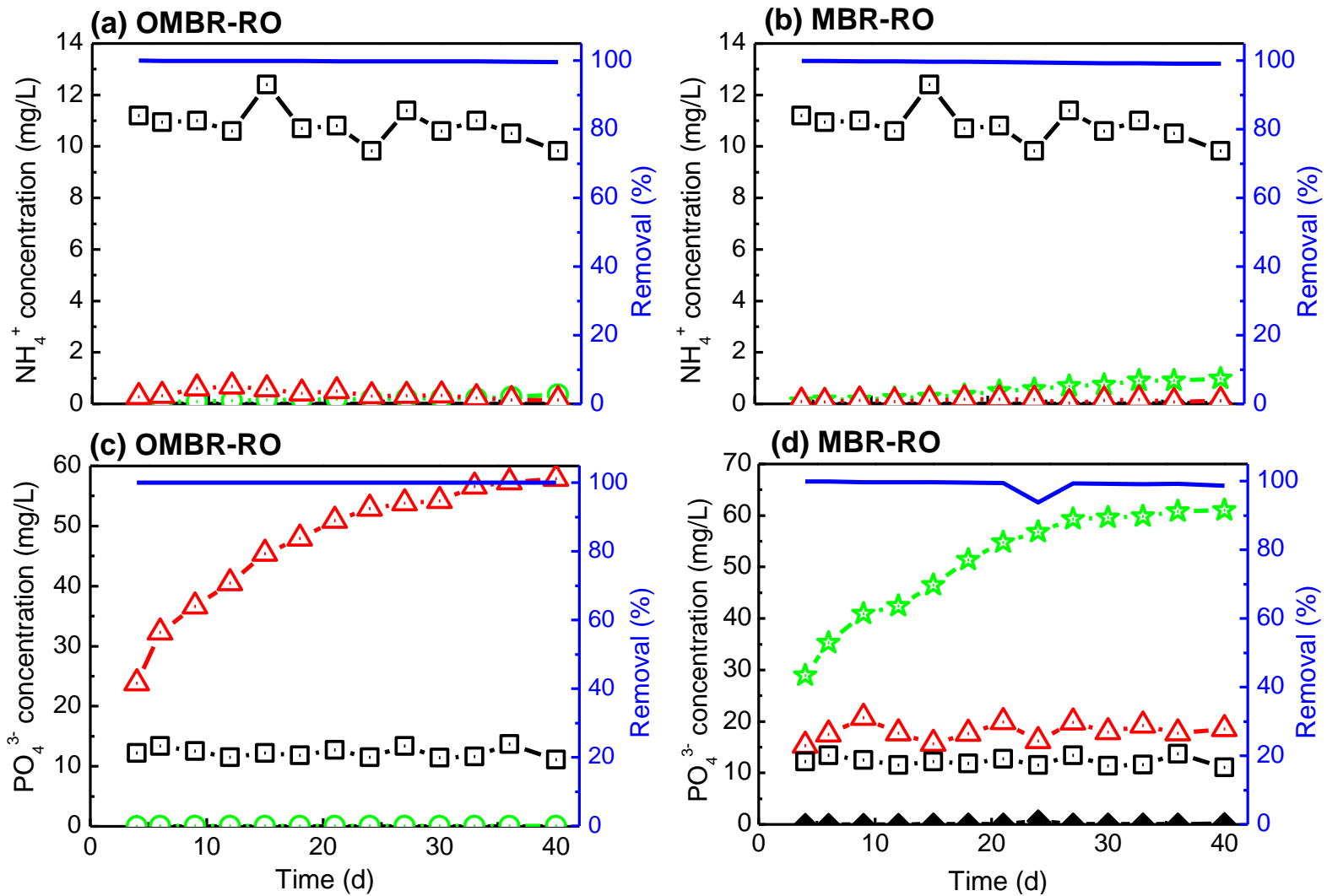

808

809 Figure 6: $\mathrm{NH}_{4}{ }^{+}$and $\mathrm{PO}_{4}{ }^{3-}$ concentrations and removal rates during OMBR-RO and

810 conventional MBR-RO operation. Experimental conditions are as described in the caption of

811 Figure 1. 
(a) OMBR-RO Bioreactor UIIIS Observed FO rejection Observed RO rejection

- $\log \mathrm{D} @ \mathrm{pH}=8$

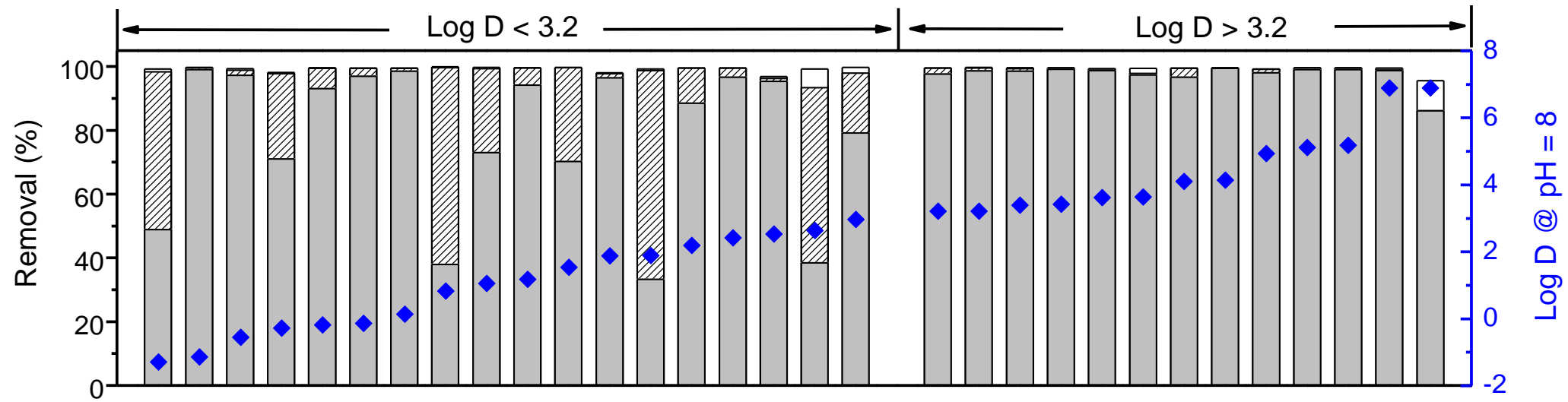

(b) MBR-RO $\square$ Bioreactor VIIIA Observed MF rejection $\square$ Observed RO rejection $\bullet \log \mathrm{D} @ \mathrm{pH}=8$

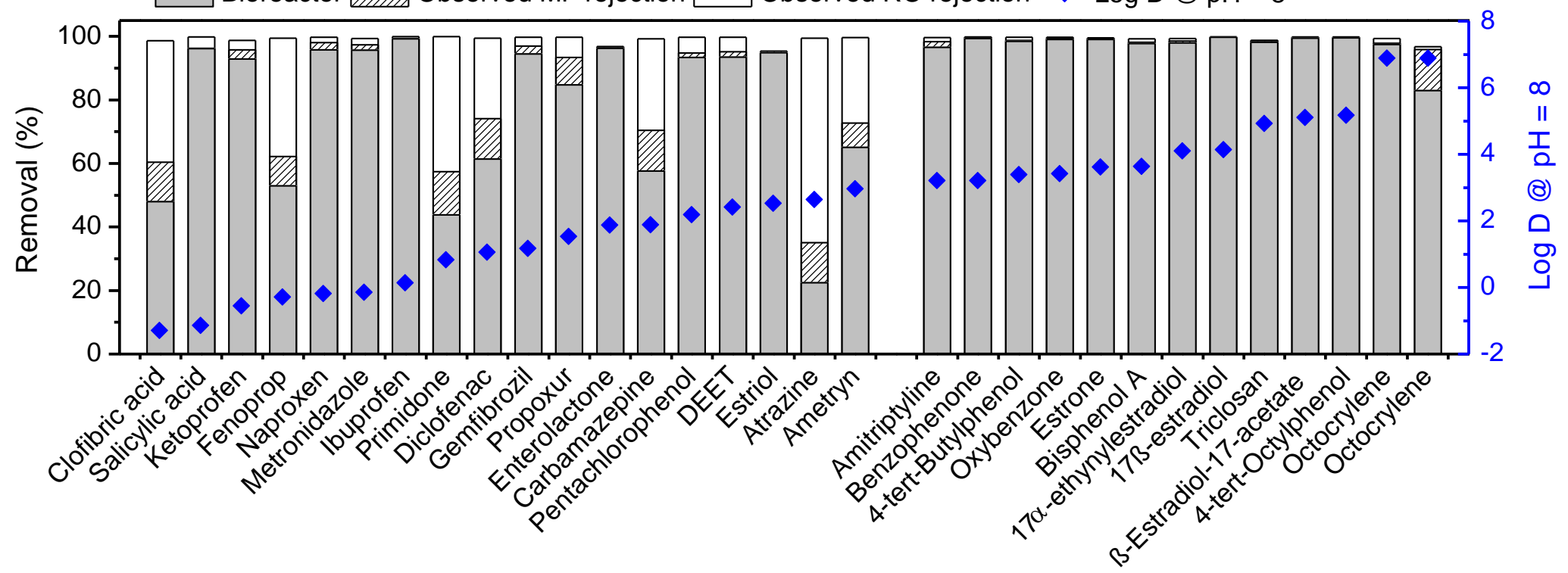

813 Figure 7: TrOC removal by different compartments of (a) OMBR-RO and (b) conventional MBR-RO. Average removal data obtained from four 814 measurements (once every ten days) were demonstrated with standard deviation in the range of 0 - 20\% (not shown in the Figure). Based on 
815 their effective octanol-water partition coefficient ( $\log \mathrm{D})$ at solution $\mathrm{pH}$ 8, the 30 TrOCs investigated were classified as hydrophobic (i.e. Log D

816 > 3.2) and hydrophilic (i.e. Log D < 3.2). Observed TrOC rejection rates do not reflect the real separation capacity of the membranes, but can be 817 used to infer their contributions to TrOC removal in the two hybrid systems. Experimental conditions are as described in the caption of Figure 1. 
(a) $\diamond$ OMBR-RO $\odot$ MBR-RO

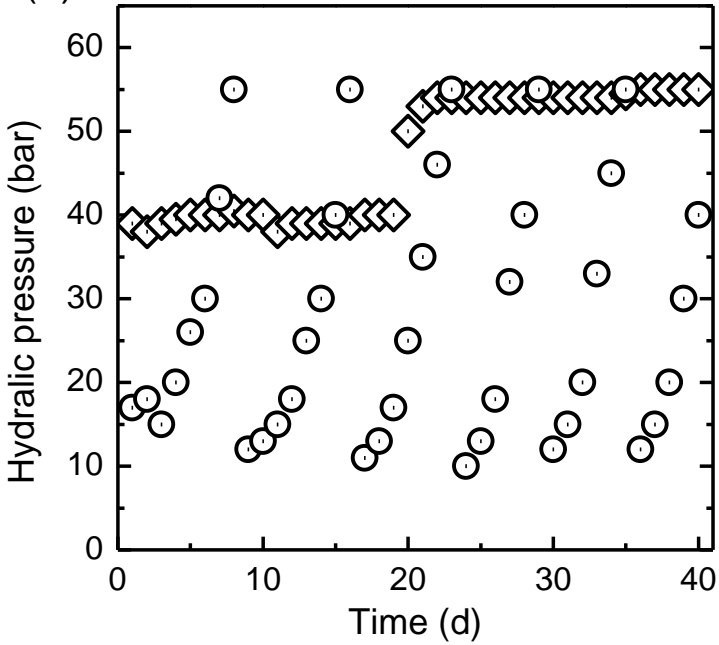

(b)

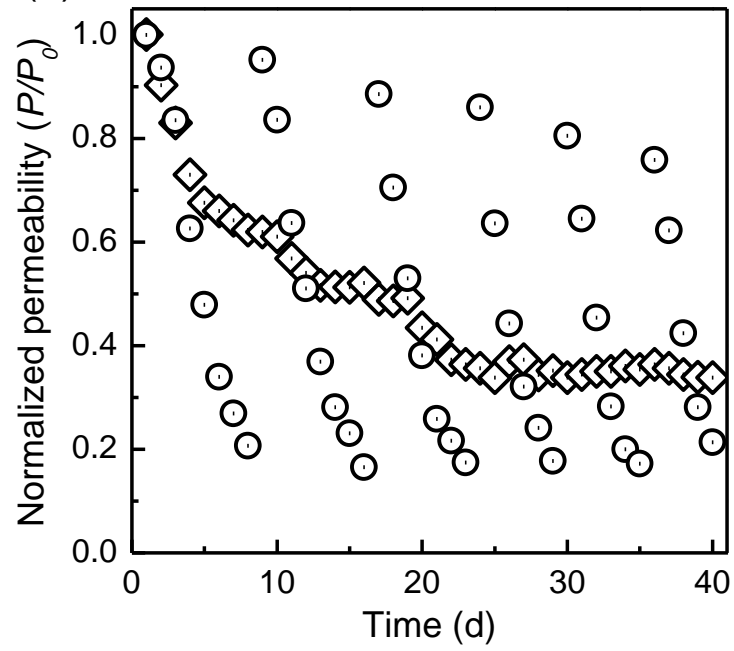

Figure 8: Hydraulic pressure (a) applied to the RO membrane and its normalized

820 permeability (b) during OMBR-RO and conventional MBR-RO operation. The normalized

821 water permeability was the ratio of the effective membrane water permeability to the initial

822 value $\left(P / P_{0}\right)$. Water flux of the RO membranes was adjusted daily to match that of OMBR.

823 On day 20, $100 \mathrm{~g} \mathrm{NaCl}$ was added to OMBR draw solution (with constant working volume of $82410 \mathrm{~L})$ to replenish draw solute loss. A new RO membrane was used once the membrane 825 normalized permeability decreased to 0.2. Experimental conditions are as described in the 826 caption of Figure 1. 


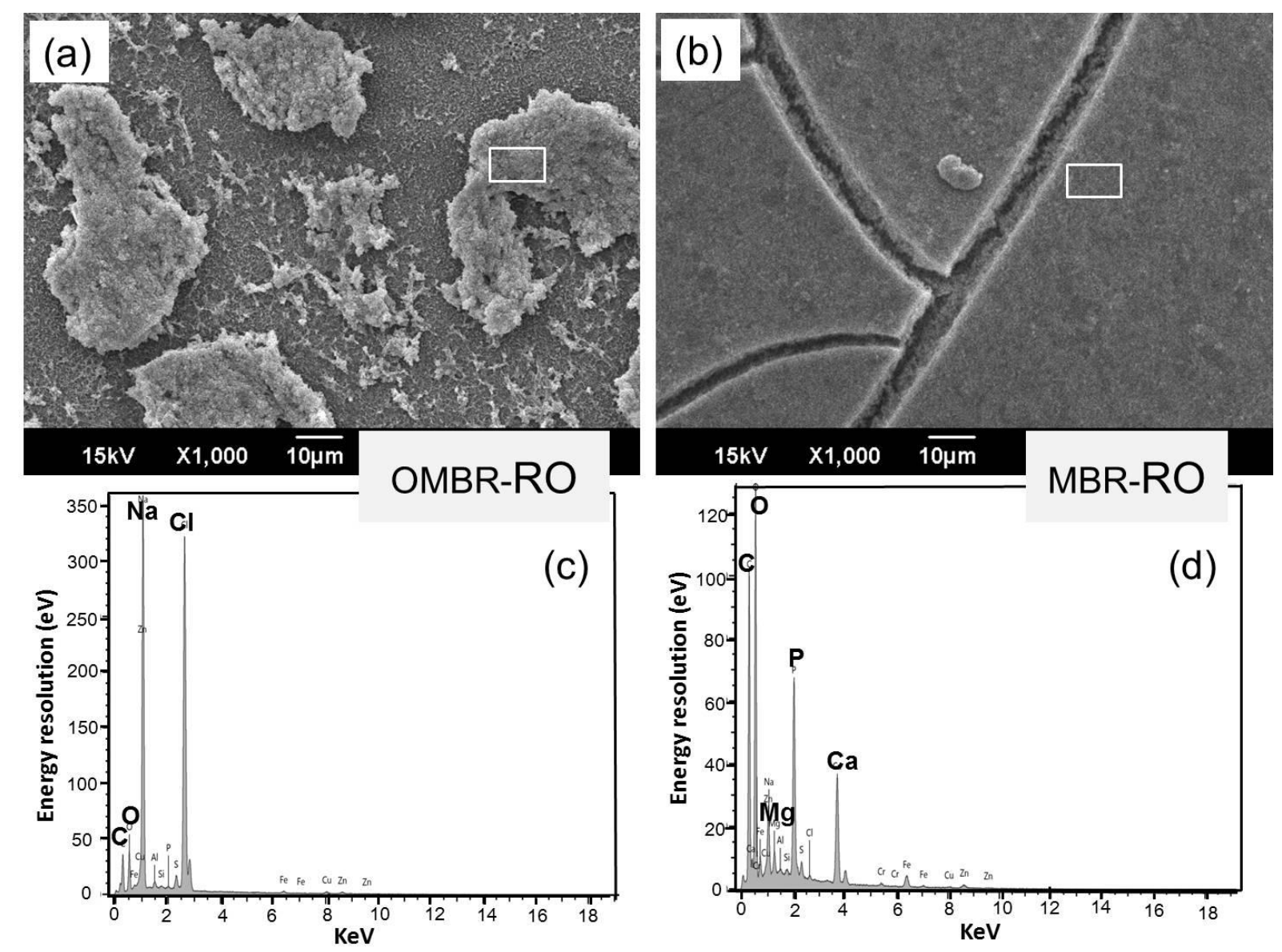

828 Figure 9: (a, b) SEM and (c, d) EDS analyses of the RO membrane surfaces at the 829 conclusion of OMBR-RO and conventional MBR-RO operation. Experimental conditions 830 were as described in the caption of Figure 1. 


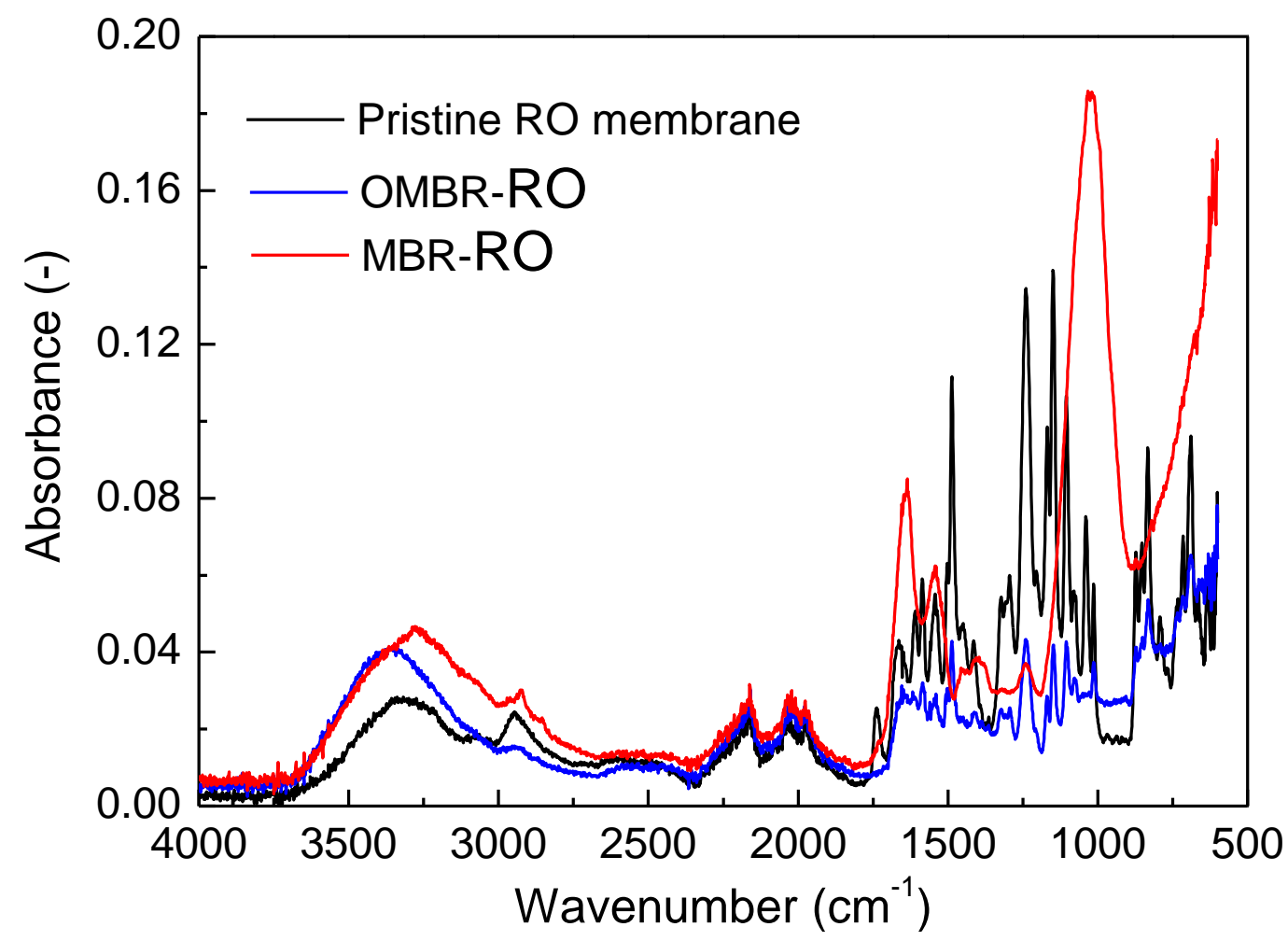

832 Figure 10: ATR-FTIR absorption spectra of the RO membrane surfaces before and after 833 OMBR-RO and conventional MBR-RO operation. Experimental conditions are as described 834 in the caption of Figure 1.

835 